\title{
Formulation, Ex-Vivo and Preclinical In-Vivo Studies of Combined pH and Ion-Sensitive Ocular Sustained In Situ Hydrogel of Timolol Maleate for the Treatment of Glaucoma
}

\author{
Prigneshkumar Patel ${ }^{1}$ (D), Gayatri Patel 2,*(D)
}

1 Manager-1, FR\&D - Formulation Research \& Development (Non -Orals), Sun Pharmaceutical Industries Ltd, Tandalja, Nima Compound, Vadodara, Gujarat, India; prigneshspatel@gmail.com (P.P)

2 Charotar University of Science and Technology, Ramanbhai Patel College of Pharmacy, Department of Pharmaceutics \& Pharmaceutical Technology, CHARUSAT Campus Changa-388 421, Gujarat, India; gayatripatel26@ gmail.com (G.P)

* Correspondence: gayatripatel26@gmail.com;

Received: 24.06.2020; Revised: 17.07.2020; Accepted: 18.07.2020; Published: 22.07.2020

\begin{abstract}
The aim of the present research work was to develop safe, effective, and stable in situ hydrogel for the ophthalmic drug delivery using the combination of ion-responsive polymer gellan gum and $\mathrm{pH}$-sensitive polymer carbopol 934P to treat glaucoma. Background: Timolol maleate is a BCS class I drug used as the first line of treatment in open-angle glaucoma. The rapid precorneal elimination of conventional formulation containing class I drugs exhibits poor therapeutic effect and bioavailability. So, in situ gelling system was formulated and characterized. Methods: Box-Behnken design was used to statistically optimize the formulation parameters and evaluate the effects of formulation attributes, namely concentration of gellan gum $\left(\mathrm{X}_{1}\right)$, the concentration of carbopol 934P $\left(\mathrm{X}_{2}\right)$ and concentration of benzododecenium bromide $\left(\mathrm{X}_{3}\right)$ on selected critical quality attributes $\left(\mathrm{Y}_{1}-\mathrm{Y}_{7}\right)$. Trial run data were statistically analyzed using the polynomial equation and response surface plots. Optimized formulation was selected based on desirability function, design space, and was further characterized and compared with the marketed formulation. Results: The concentration of both polymers showed a synergistic positive impact on viscosity at the non-physiological and physiological conditions. Trial runs showed controlled drug release with diffusion-controlled mechanism and good mucoadhesive strength due to the presence of Carbopol 934P. The preservative benzododecenium bromide showed the ability to enhance trans-corneal permeation. The optimized formulation has appeared as a clear solution at the non-physiological condition and clear gel at the physiological condition with an acceptable $\mathrm{pH}$ range of 5-6. Other quality attributes like rheological properties, gelling capacity, texture analysis, Isotonicity, contact angle, sterility, antimicrobial efficacy, and stability were found in desires values for the ocular application. The safety of in situ gel for human use was confirmed by ocular irritation and histopathology studies in the rabbit eyes. The intraocular pressure (IOP) reduction with optimized formulation was found comparable and less fluctuating compared to ophthalmic gel-forming marketed solution of timolol maleate (TIMOPTIC-XE ${ }^{\circledR}$ ). Conclusion: The cross-linking between Carbopol 934P with Gellan gum in the formation showed more viscous gelling at the physiological condition to provide long pre-corneal residence time. The optimized formulation exhibited all the desirable attributes of an ideal ophthalmic in situ gelling formulation, exhibited in-vitro controlled drug release, good gelling capacity, and was found to be stable and non-irritant to the eye.
\end{abstract}

Keywords: Glaucoma; Ion responsive; Box-Behnken design; Controlled release.

(C) 2020 by the authors. This article is an open-access article distributed under the terms and conditions of the Creative Commons Attribution (CC BY) license (https://creativecommons.org/licenses/by/4.0/). 


\section{Introduction}

Glaucoma is a common eye condition that can cause irreversible blindness if not diagnosed and treated within the early stage. Glaucoma is related to an increase in intraocular pressure (IOP). The conventional eye drops for the treatment is very useful but still have some problems like low bioavailability (1-5\%), requires frequent instillation of drops, reflex tearing, and blinking[1,2]. The disadvantages of eye drop as a delivery system led to investigations of novel and alternative devices and delivery systems [3]. Also, due to the need to deliver the dose to the site by solution and resultant faster elimination of the drug, the patients have to suffer from many problems [4]. Due to these drawbacks, traditional methods of delivery of the drugs are replaced by alternative methods of delivery to fulfill the unmet needs [5,6]. Drug delivery in the form of in-situ gelling offers a substitute to eye drops as this concept decreases the dosing frequency. Such a delivery system provides phase transition invivo from sol to gel within the impasse of the eye when the polymer in eye drops gives a response to the stimuli and forms gel[7,8].

In situ forming gels are formulations applied as solutions, sols or suspensions that undergo gelation after installation due to physicochemical changes inherent to the physiological parameters. Parameters that can change and trigger the gel formation include $\mathrm{pH}$, temperature, and ionic strength [4,9]. The present work describes the combination approach for gelling by $\mathrm{pH}$ and ionic strength. $\mathrm{pH}$-sensitive in situ gelling is achieved by a change in $\mathrm{pH}$. Most of the anionic pH-sensitive polymers (carbopol) swell as the external $\mathrm{pH}$ increases due to proton acceptance in the eye environment [10]. On the other hand, ion stimulated gelling is activated by a change in the ionic strength or due to the presence of ions in the tear fluid. Once it forms a gel, it can stand up to the drainage process and amplify residence time [11]. An effort was made using a combination of $\mathrm{pH}$ and ion stimulated gelling by Gupta et al. when they formulated in situ gel of Sparfloxacin with a combination of chitosan, which is $\mathrm{pH}$ sensitive and gellan gum which is ion-sensitive[12].

Glaucoma is an eye disease that results in damage to optic nerve and vision loss. Worldwide glaucoma is the second leading cause of blindness after cataracts. Currently, the treatment of choice of glaucoma is to reduce IOP [13]. Timolol maleate has been established as the first line of the drug in the treatment of glaucoma. Even after the advent of the latest drugs like prostaglandin analogs and alpha- 2 agonists, timolol remains the first choice due to cost-effective reason. It is a beta-adrenergic blocker that is non-selective between beta1 and beta- 2 adrenergic receptors. It has no issue with solubility and permeability, and it effectively lowers the IOP, diminishes blood pressure by delaying both the receptors and reducing sympathetic discharge. It also develops an adverse chronotropic and inotropic movement. Lifelong treatment with topical drops is usually required in the treatment of glaucoma. Hence, reduction in its dosing frequency can improve patient compliance and therapy $[14,15]$.

In order to study the combined effect of $\mathrm{pH}$ and ion stimulated gelling approaches, we have used carbopol 934 and Gelrite ${ }^{\circledR}$ Gellan gum for $\mathrm{pH}$ and ion-sensitive gelling, respectively. Carbopol 934 is a synthetic polyacrylic acid polymer which shows a sol to gel transition in aqueous solution as the $\mathrm{pH}$ is raised above its $\mathrm{pKa}$ of 5.5. Additionally, it interacts with mucin in the tear film to increase drug retention [16,17]. Gelrite ${ }^{\circledR}$ (deacetylated gellan gum) is one of the most promising ion-sensitive in situ gelling polymer and an approved ophthalmic excipient. It forms a clear gel in the presence of mono or divalent cations. 
Rheological properties of gellan gum, such as thixotropy, pseudo-plasticity, and thermoplasticity, are advantageous for its use in ophthalmic formulations [18,19].

The aim of the present research work was to develop safe, effective, and stable in situ gel for the ophthalmic drug delivery using the combination of ion-responsive polymer gellan gum and $\mathrm{pH}$-sensitive polymer carbopol 934P to treat glaucoma. The developed formulation was characterized and compared with ophthalmic gel-forming marketed solution of timolol maleate (TIMOPTIC-XE ${ }^{\circledR}$ ). We have applied the quality by design approach for the optimization of the formulation. A complete characterization and assessment have been performed for developed formulation.

\section{Materials and Methods}

\subsection{Materials.}

Timolol Maleate was received as a gift sample from Centaur Pharmaceutical Limited (Mumbai). Gellan gum was procured from CP Kelco (Atlanta), Sodium Hydroxide was acquired from Merck KGaA (USA). Mannitol was attained from SD Fine-chem Limited (Mumbai). Carbopol 934P was purchased from Lubrizol Corporation. Benzododecinium Bromide was purchased from Vapi Care Pharma Pvt. Ltd. (Vapi). All other chemicals and reagents utilized were of analytical grade.

\subsection{Methods.}

\subsubsection{Formulation development.}

In the present investigation, Box-Behnken design as an optimization tool was applied for formulation development. This design is appropriate for three independent variables at their three levels. Through this design, the effect of three formulations attributes, namely concentration of gellan gum $\left(\mathrm{X}_{1}\right)$, the concentration of carbopol 934P $\left(\mathrm{X}_{2}\right)$, and concentration of benzododecenium bromide $\left(\mathrm{X}_{3}\right)$ was investigated on selected critical quality attributes. The independent and dependent variables for the delivery system are described in Table 1. As per Box Behnken design, total17 controlled experimental trial runs were conducted to observe respective dependant variables as described in Table 2. The independent variables selected with their low (-1), medium (0), and high (+1) levels were chosen based on the results from prior experience, preliminary experimentation, and literature survey. Data from designed trial runs were statistically analyzed using the polynomial equation, analysis of variance, and response surface plots utilizing Design Expert software (Version 9.0.0, Stat-Ease Inc., Minneapolis, $\mathrm{MN})$. Optimized formulation was selected based on the desirability function and design space. The non-linear polynomial equation used for data analysis is shown in equation 1.

$$
Y=b_{0}+b_{1} X_{1}+b_{2} X_{2}+b_{3} X_{3}+b_{12} X_{1} X_{2}+b_{13} X_{1} X_{3}+b_{23} X_{2} X_{3}+b_{11} X_{1}^{2}+b_{22} X_{2}^{2}+b_{33} X_{3}^{2}-- \text { (Eq. } 1 \text { ) }
$$

Where $\mathrm{Y}$ is the measured response related to each factor level combination; $\mathrm{b}_{0}$ is an intercept; $b_{1}$ to $b_{33}$ are evaluated regression coefficients computed from the distinguished experimental values of $\mathrm{Y}$; and $\mathrm{X}_{1}, \mathrm{X}_{2}$, and $\mathrm{X}_{3}$ are the coded levels of independent variables. The terms $\mathrm{X}_{1} \mathrm{X}_{2}$ and $\mathrm{X}^{2} \mathrm{i}(\mathrm{i}=1,2$, or 3 ) represent the interaction and quadratic terms, individually. The most impacts $\left(X_{1}, X_{2}\right.$, and $\left.X_{3}\right)$ represents the average results of changing one factor at a time from its low to high value. The interaction terms $\left(X_{1} X_{2}\right)$ indicates how the response alters when two or more factors are simultaneously changed [20]. 
Table 1. Description of independent and dependent variables for formulation development.

Translation of coded values in actual units

\begin{tabular}{|c|c|c|c|}
\hline \multirow[t]{2}{*}{ Independent variables } & \multicolumn{3}{|c|}{ Levels used, actual (coded) } \\
\hline & Low & Medium & High \\
\hline Concentration of Gellan gum $(\% \mathrm{w} / \mathrm{v})=\mathrm{X}_{1}$ & $0.25(-1)$ & $0.5(\mathbf{0})$ & $0.75(+1)$ \\
\hline Concentration of Carbopol 934P $(\% \mathrm{w} / \mathrm{v})=\mathrm{X}_{2}$ & $0.15(-1)$ & $0.30(\mathbf{0})$ & $0.45(+1)$ \\
\hline Concentration of Benzododecinium bromide $(\% \mathrm{w} / \mathrm{v})=\mathrm{X}_{3}$ & $0.006(-1)$ & $0.012(\mathbf{0})$ & $0.018(+1)$ \\
\hline Dependent variables & \multicolumn{3}{|l|}{ Constraints } \\
\hline $\mathrm{Y}_{1}=$ Viscosity at non-physiological condition $\left(25^{\circ} \mathrm{C} \pm 2, \mathrm{pH} 5\right)$ & \multicolumn{3}{|c|}{$\mathrm{Y}_{1}=75$ to $125 \mathrm{cps}$} \\
\hline $\mathrm{Y}_{2}=$ Viscosity at physiological condition $\left(35^{\circ} \mathrm{C} \pm 2, \mathrm{pH} 7.4\right)$ & \multicolumn{3}{|c|}{$\mathrm{Y}_{2}=3200$ to $3600 \mathrm{cps}$} \\
\hline $\mathrm{Y}_{3}=$ Cumulative $\%$ drug release at $1 \mathrm{hr}\left(\mathrm{Q}_{1}\right.$ in $\left.\%\right)$ & \multicolumn{3}{|c|}{$\mathrm{Y}_{3}=10$ to $12 \%$} \\
\hline $\mathrm{Y}_{4}=$ Time required to release $90 \%$ of drug ( $\mathrm{t}_{90}$ in $\min$ ) & \multicolumn{3}{|c|}{$\mathrm{Y}_{4}=1200$ to 1250 minutes } \\
\hline $\mathrm{Y}_{5}=$ Mucoadhesive Strength $(\operatorname{gram}(\mathrm{s}))$ & \multicolumn{3}{|c|}{$\mathrm{Y}_{5}=22$ to $25 \operatorname{gram}(\mathrm{s})$} \\
\hline $\mathrm{Y}_{6}=$ Gel strength (seconds) & \multicolumn{3}{|c|}{$\mathrm{Y}_{6}=35$ to 40 seconds } \\
\hline $\mathrm{Y}_{7}=$ Rate of Permeability (sq.cm/sec.) & \multicolumn{3}{|c|}{$\mathrm{Y}_{7}=1.250$ to $1.450 \mathrm{sq} . \mathrm{cm} / \mathrm{sec}$} \\
\hline
\end{tabular}

Table 2. Box Behnken design layout with respective dependent variables $\left(\mathrm{Y}_{1}-\mathrm{Y}_{7}\right)$ for ocular in situ gelling

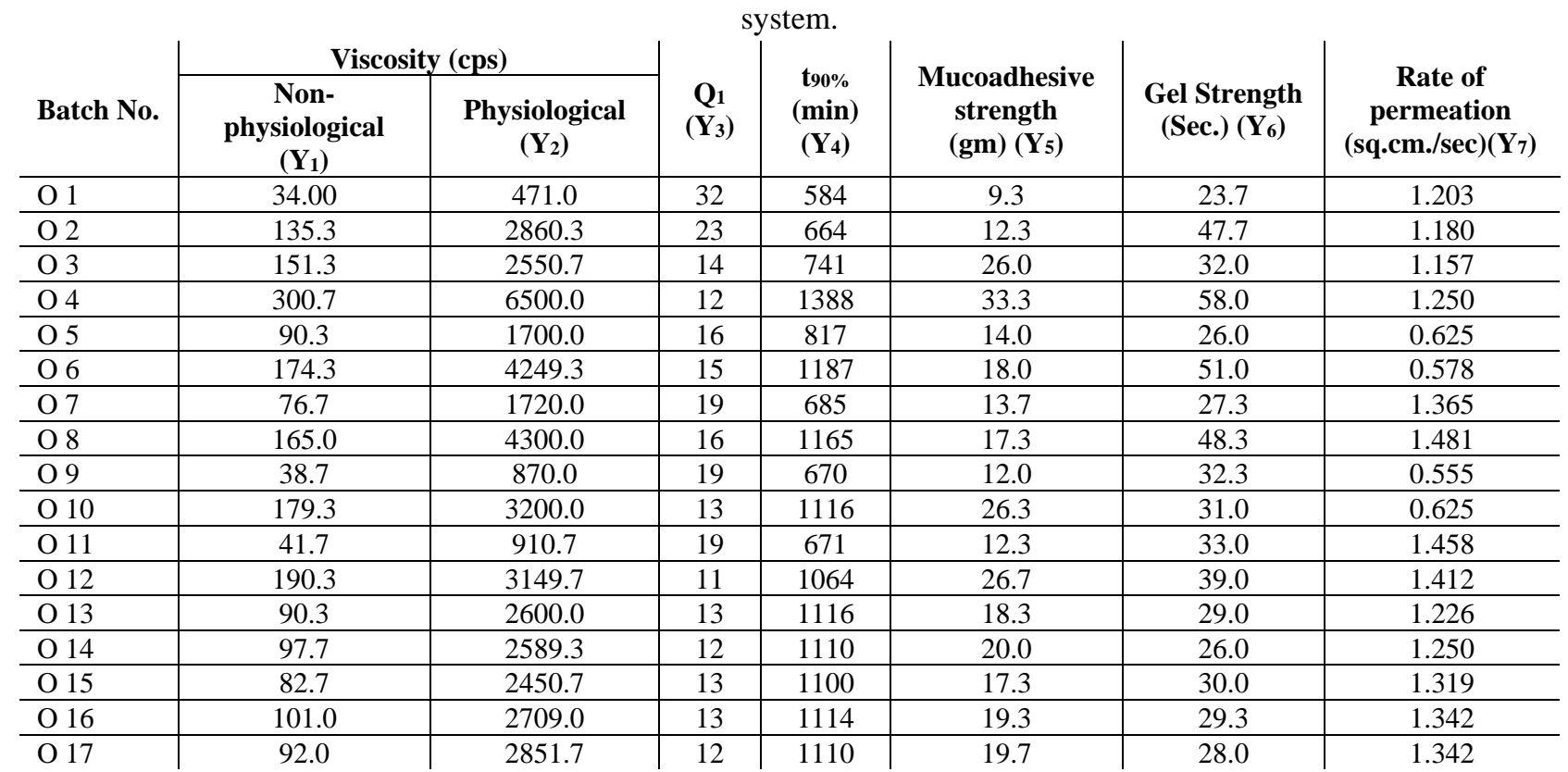

2.2.2. Composition of in-situ gel.

Preparations were formulated by mixing two phases. In the first phase, the required quantity of mannitol was dissolved in $45 \%$ of the total volume of batch size in deionized water and stirred for $30 \mathrm{~min}$. In the above solution, the required quantity of gellan gum and/or carbopol was added with subsequent stirring for 60 minutes at $70^{\circ} \mathrm{C}$ to $80^{\circ} \mathrm{C}$. The second phase was prepared by dissolving the required quantity of Timolol maleate and benzododecinium bromide to form $45 \%$ of the total volume of batch size in deionized water. Upon cooling of the first phase, to room temperature, the second phase was added in it and mixed. The $\mathrm{pH}$ was adjusted between 5 and 6 by $0.1 \mathrm{~N}$ Sodium hydroxide solution, and the final bulk volume was made up with deionized water. Bulk preparations were sterilized by autoclave $\left(121^{\circ} \mathrm{C}, 15 \mathrm{psi}\right.$ for 20 minutes) and filled in LDPE (Low-density polyethylene) bottles for further study [12].

\subsection{Evaluation of experimental design batches.}

\subsubsection{Determination of viscosity.}

The viscosity of formulation was determined by Brookfield viscometer (LV DVII+PRO model) at $100 \mathrm{rpm}$ utilizing spindle number 31 at room temperature $\left(25 \pm 2^{\circ} \mathrm{C}\right)$ and spindle 
number 64at physiological condition $\left(37 \pm 2^{\circ} \mathrm{C}\right)$. This was done for comparative assessment of viscosity of the formulations at physiological and non-physiological conditions $[21,22]$.

2.3.2. In- vitro drug release study of the ocular in-situ gelling system.

In-vitro drug release study was performed through the cellophane membrane using a modified USP XXIII dissolution apparatus [23]. It was performed using simulated tear fluid as a medium. The membrane used was previously saturated with a dissolution medium. Five ml of the formulation was accurately taken into this assembly. The glass cylinder was suspended in $50 \mathrm{ml}$ of the specified dissolution medium at $37 \pm 0.5^{\circ} \mathrm{C}$ so that the membrane just touches the receptor medium surface. The receiving medium was stirred at $50 \mathrm{rpm}$. A sample was placed evenly on the surface of the membrane in the donor compartment. Aliquots were withdrawn at hourly intervals till 24 hours and replaced by an equal volume of dissolution medium to maintain the sink condition. The aliquots were diluted with diluents medium (water and acetonitrile in the ratio of 60:40) up to $50 \mathrm{ml}$ followed by sonication for about 15-20 minutes and analyzed for Timolol maleate concentration using optimized HPLC conditions against working standard area.

\subsubsection{Measurement of mucoadhesive strength.}

Mucoadhesive strength was determined by calculating the strength necessary to remove the preparation from mucosal tissue utilizing an adapted technique given by Yong et al. [24]. An area of corneal tissue membrane, along with part of the conjunctiva, was extracted from the eyes of a goat. The mucosal tissue was immediately tied onto each glass vial using a thread keeping mucosal side on the outer side. In another vial with a section of mucosal tissue was placed in an inverted position while the first vial was placed on a height-adjustable pan. The formulation gel was placed between the mucosal tissues of both vials. It was adjusted in such a way that the membrane surfaces of both the vials came in close contact. The mucoadhesive force is the minimum weight required to detach two vials (Eq. 2). The mucosal tissue pieces were changed for each measurement. All measurements were performed in triplicate.

$$
\text { Detachment Stress }(\text { dyne } / \mathrm{cm})=\frac{(\mathrm{m} * \mathrm{~g})}{\mathrm{A}}
$$

Where $\mathrm{m}$ is the weight required for detachment in grams; $\mathrm{g}$ is the acceleration due to gravity taken as $980 \mathrm{~cm} / \mathrm{s}^{2}$, and $\mathrm{A}$ is the area of tissue exposed in sq. $\mathrm{cm}$.

\subsubsection{Gel strength Measurements.}

Gel strength was measured by the gel strength gadget device [24]. The different formulations were converted into a gel at $37^{\circ} \mathrm{C}$. Gel strength, i.e., the viscosity of the gel at physiological condition, was analyzed by the time(s) taken by the probe to drop down $5 \mathrm{~cm}$ over the gel $(n=3)$.

\subsubsection{In-vitro trans-corneal permeation study.}

In-vitro trans-corneal permeation study was carried out within the corneal eyeballs of a goat. Corneal tissue samples were embedded in Franz diffusion cell, which comprises of both donor and receptor compartments. The isolated cornea was fixed by sandwiching the neighboring scleral tissue between the donor and receptor compartments in a way that its 
epithelial surface confronted the donor compartment. The upper compartment becomes a patron/donor chamber in which the formulation was positioned. The lower compartment assisted as a receiver chamber having $15 \mathrm{ml}$ of simulated tear fluid (STF) kept at $37 \pm 0.5^{\circ} \mathrm{C}$. The elutriate of $2 \mathrm{ml}$ was collected at periodic time intervals for up to $4 \mathrm{hrs}$. The samples were analyzed for drug content by HPLC [25].

\subsection{Characterization of optimized in-situ gel.}

\subsubsection{Clarity and $\mathrm{pH}$.}

The clarity test was performed by visually observing the optimized formulation alternatively against light and dark background. The $\mathrm{pH}$ of all ocular in-situ gel was measured with a standard calibrated digital $\mathrm{pH}$ meter at $25 \pm 1^{\circ} \mathrm{C}$. All measurements were done in triplicate [12].

\subsubsection{Drug content.}

The drug content was determined by taking $1 \mathrm{ml}$ of the formulation sample and added into $50 \mathrm{ml}$ of volumetric flask. The sample was diluted with diluents medium (water and acetonitrile in the ratio of 60:40) up to $50 \mathrm{ml}$ followed by sonication for about 15-20 minutes and analyzed for Timolol maleate concentration using optimized HPLC conditions against working standard area [23].

\subsubsection{In-vitro gelling capacity.}

In-vitro Gelling Capacity test was carried out by two methods. In flowability method a test tube upsetting technique defined by Jeong et al., was utilized to unevenly decide the phase nature of formulation at three different storage temperature points viz. $5 \pm 1^{\circ} \mathrm{C}$ (fridge temperature), $25 \pm 1^{\circ} \mathrm{C}$ (room temperature) and $37 \pm 1^{\circ} \mathrm{C}$ (physiological temperature). In the visual method, one $\mathrm{ml}$ of optimized formulation was added to a vial containing two $\mathrm{ml}$ of STF kept at $37 \pm 1{ }^{\circ} \mathrm{C}$ temperature. As the formulation comes in contact with STF, it converts into a stiff gel, which was observed and graded according to its stiffness [22].

\subsubsection{Isotonicity.}

Isotonicity of the optimized formulation was measured by observing hemolysis in the blood. The formulation was mixed with few drops of blood and observed under the optical microscope at $45 \mathrm{X}$ magnification. The observation was compared with the effect on blood illustrated by hypotonic, hypertonic, and normal saline solution [12].

\subsubsection{Texture analysis.}

Texture analysis of optimized formulation at physiological condition (STF pH 7.4, $37^{\circ} \mathrm{C}$ ) was carried out on Brookfield QTS Texture Analyzer. Texture analysis basically evaluates the mechanical properties where the optimized formulation was subjected to controlled force from which a deformation curve is generated. The analysis was performed in triplicate [21]. 


\subsubsection{Measurement of contact angle.}

The contact angle measurement of optimized formulation was conducted with CAM101 contact angle optical goniometer (Attension Theta, KSV Instruments, Finland). The contact angle was measured in both hydrophilic and hydrophobic surfaces and compared with the marketed formulation of the drug. The contact angle at the hydrophilic and hydrophobic surface indicates the interactions at the ocular interface and spreadability of the formulation [26].

\subsubsection{Histopathological evaluation of cornea.}

The goat cornea was kept in contact with optimized formulation for 24 hours. These corneas were utilized for histopathological assessment. The cornea was placed in $10 \%$ buffered formalin ( $\mathrm{pH}$ 7.4) and inserted in paraffin. Paraffin parts were pieced on the plates and blemished with hematoxylin and eosin (HE). Segments were inspected under the optical microscope to identify any impairment to the ocular tissue [27].

\subsubsection{Sterility test.}

The test for sterility was evaluated by Method-B Direct Inoculation as per Indian Pharmacopoeia. An optimized formulation was withdrawn from the test holder with a sterile pipette. An amount of $2 \mathrm{ml}$ of the optimized formulation was inoculated directly into the culture medium and was incubated for 14 days. The cultures were observed for microbial growth during the 14 days of incubation. Negative control was also performed as described above to evaluate the sterility of media [28].

\subsubsection{Antimicrobial effectiveness test.}

Antimicrobial effectiveness test was carried out on the optimized formulation utilizing the agar diffusion method by cup plate method with standard organisms Staphylococcus aureus (ATCC 6538P) and Escherichia coli (ATCC 10536). The marketed sterile formulation of the timolol maleate was taken as a standard for the comparison with the optimized formulation. Both marketed and optimized formulations were diluted suitably to 5 and $30 \mu \mathrm{g} / \mathrm{ml}$ solution and were poured into cups of agar plates. After 2 hours of diffusion of the solution, the agar plates were incubated at $37^{\circ} \mathrm{C}$ for $24 \mathrm{hrs}$. The zone of inhibition (ZOI) was measured and compared. The tests were carried in triplicate, and the mean inhibition zone \pm S.D. were calculated. The positive and negative controls were implemented during the study [29]. The percentage efficiency for the optimized ocular in situ gelling systems was calculated using equation 3.

$$
\% \text { Efficiency }=\frac{\text { zOI of test }}{\text { ZOI of standard }} \times 100 \text {------------------------ }(\text { Eq.3) }
$$

\subsubsection{Accelerated Stability study.}

Accelerated stability study was conducted on optimized formulation according to ICH (International Conference on Harmonization) guidelines. An optimized formulation in its final primary packaging container was kept in stability chambers at $40^{\circ} \mathrm{C} \pm 2^{\circ} \mathrm{C} /$ not more than (NMT) $25 \% \mathrm{RH}$. The samples were withdrawn at 0,3 , and 6 months interval and were analyzed for physical appearance, clarity, viscosity, related substances, $\mathrm{pH}$, osmolality, in-vitro gelling capacity, in-vitro drug release, and assay. The logarithms of percent drug remaining were 
calculated and plotted against time in days. The degradation rate constant was calculated with equation slope $=\mathrm{K} / 2.303$, where $\mathrm{K}$ is a degradation rate constant [12].

\subsubsection{Ocular pharmacodynamic study.}

Rabbits (New Zealand white, Male, 2.5 to $3.2 \mathrm{~kg}$ ) were used for a comparative study of both optimized and marketed formulations. Animals were treated as prescribed in the NIH publication "Guide for the Care and Use of Laboratory Animals". All experiments conformed to the ARVO Resolution on the Use of Animals in Research. They were carried out under veterinary supervision, and the protocols were approved by the Ethical-Scientific Committee of the University. The animals were housed individually in standard cages in a room with normal controlled lighting, at normal room temperature $\left(16-22^{\circ} \mathrm{C}\right)$ and humidity $(30-70 \%$ relative humidity), with no restriction of food or water. During the experiments, the rabbits were placed in restraining boxes to which they had been habituated, in a room with dim lighting; they were allowed to move their heads freely, and their eye movements were not restricted [30,31].

Rabbits were divided into two groups $(n=3)$ based on body weights. The optimized formulation was instilled in the left eye of group 1 rabbits, whereas the commercially available formulation was instilled in the left eye of group 2 rabbits. In all rabbits, the right eye was instilled with placebo in the form of a vehicle. The dosing was provided with an eyedropper $(35-50 \mu \mathrm{L})$. During the study of formulation, the rabbit eyes were assessed every day for tearing, discharge, blepharospasm (twitchy and forceful blinking of the eyelids), ptosis (eyelid drooping), and conjunctival redness, which are all signs of ocular discomfort. The assessment was carried as mentioned in OECD (Organization for Economic Co-operation and Development [OECD, 1987]) guidelines. At a predetermined time period, the IOP measurements were performed using a tonometer (TONOVET, Finland). The measurement was done in triplicate [25].

\section{Results and Discussion}

\subsection{Evaluation of experimental design batches.}

In the present investigation for formulation development, Box-Behnken design as an optimization design was used for three selected material attributes to study their effect on seven selected quality attributes, as shown in Table 1. All the responses (dependent variables) obtained for the 17 trial batches were at the same time fitted to the quadratic response surface model utilizing Design Expert (Version 9.0.0, Stat-Ease Inc., Minneapolis, MN). The observed responses for $\mathrm{Y}_{1}$ to $\mathrm{Y}_{7}$ are revealed in Table 2.

\subsubsection{Statistical analysis for $\mathrm{Y}_{1}$ (Viscosity at non- physiological condition).}

The obtained value for viscosity at the non-physiological condition for all 17 trial runs O1-O17 varied from 34 to $300 \mathrm{cps}$. The response $\left(\mathrm{Y}_{1}\right)$ observed at different levels of three independent variables were exposed to multiple reversion to give a quadratic polynomial equation as per mention in the above values are shown in Table 3. The non-linear model produced for viscosity at non-physiological conditions was found to be significant with an Fvalue of 49.62, $\mathrm{p}$-value $<0.0001$, an $\mathrm{R}^{2}$ value of 0.9845 . Both $\mathrm{X}_{1}(52.87)$ and $\mathrm{X}_{2}$ (71.50) has a higher value of co-efficient. These two variables $\mathrm{X}_{1}$ and $\mathrm{X}_{2}$ were also found to be significant 
in the prediction of $\mathrm{Y}_{1}$. These two variables have a positive impact on viscosity at the nonphysiological condition. The effect of carbopol 934P on viscosity at non-physiological atmosphere is about 1.4 fold as compare to the effect of gellan gum. Thus, it can be said that if carbopol 934P is used at higher concentrations, then it would improve the consistency or gelling property of formulation at the non-physiological condition. It is also evident that other independent variables $\mathrm{X}_{3}$ - Benzododecenium bromide (BDB) did not show a significant effect on viscosity. The results are depicted in Figure 1.

\subsubsection{Statistical analysis of viscosity at physiological condition $\left(\mathrm{Y}_{2}\right)$.}

The obtained value for viscosity at the physiological condition for all 17 trial runs O1O17 changed from 471 to $6500 \mathrm{cps}$. This result obviously demonstrates that viscosity in the physiological environment influenced by the independent variables chosen for examination. The response $\left(\mathrm{Y}_{2}\right)$ observed at different levels of three independent variables were exposed to manifold reversion to give a quadratic polynomial value shown in Table 3. The non-linear model produced for viscosity at physiological conditions was found to be significant with an F-value of 58.60, $\mathrm{p}$-value $<0.0001$, and $\mathrm{R}^{2}$ value of 0.9869 . The overhead calculation evidently replicates the wide variety of values of different co-efficient (b). Out of three independent variables, $X_{3}$ has a lower value of co-efficient. This variable $X_{3}(p>0.05)$ was found to be insignificant in the prediction of $Y_{2}$. Out of three independent variables, the $X_{1}$ (1433) and $X_{2}$ (1286) has a higher value of co-efficient. These two variables were $X_{1}$, and $X_{2}$ was also found to be significant in the prediction of $\mathrm{Y}_{2}$. These two variables have a positive effect on viscosity at physiological conditions. Thus variable $\mathrm{X}_{1}$, i.e., gellan gum, has a prominent effect on viscosity at physiological condition $\left(\mathrm{Y}_{2}\right)$. It is also apparent that other independent variables $\mathrm{X}_{3}$-Benzododeceniumbromide (BDB) did not show an effect on viscosity and were nonsignificant. The results are depicted in Figure 1.

Table 3. Results of regression analysis for variables of ocular in situ gelling systems $\left(\mathrm{Y}_{1}-\mathrm{Y}_{4}\right)$.

\begin{tabular}{|c|c|c|c|c|c|c|c|c|}
\hline \multirow[t]{2}{*}{$\begin{array}{l}\text { Independent } \\
\text { variables }\end{array}$} & \multicolumn{2}{|c|}{$\begin{array}{r}\text { Viscosity at non- } \\
\text { physiological = } Y_{1}\end{array}$} & \multicolumn{2}{|c|}{$\begin{array}{c}\text { Viscosity at physiological }= \\
\mathbf{Y}_{2}\end{array}$} & \multicolumn{2}{|c|}{$\mathbf{Q}_{1}=\mathbf{Y}_{3}$} & \multicolumn{2}{|c|}{$\mathbf{t}_{90 \%}=\mathbf{Y}_{4}$} \\
\hline & p value & Coefficients & p value & Coefficients & p value & Coefficients & p value & Coefficients \\
\hline Intercept & $<0.0001$ & 92.73 & $<0.0001$ & 2640.13 & 0.006 & 12.60 & $<0.0001$ & 1110.00 \\
\hline $\mathrm{X}_{1}$ & $<0.0001$ & 52.88 & $<0.0001$ & 1433.50 & 0.061 & -1.88 & $<0.0001$ & 197.13 \\
\hline $\mathbf{X}_{2}$ & $<0.0001$ & 71.50 & $<0.0001$ & 1286.04 & 0.004 & -5.38 & $<0.0001$ & 215.00 \\
\hline $\mathbf{X}_{3}$ & 0.8106 & -1.13 & 0.9338 & 7.63 & 0.775 & 0.25 & 0.0151 & -25.63 \\
\hline $\mathbf{X}_{12}$ & 0.1026 & 12.00 & 0.0169 & 390.00 & 0.186 & 1.75 & $<0.0001$ & 141.75 \\
\hline $\mathbf{X}_{13}$ & 0.8702 & 1.08 & 0.9529 & 7.67 & 0.688 & -0.50 & 0.0455 & 27.50 \\
\hline $\mathbf{X}_{23}$ & 0.7635 & 2.00 & 0.8609 & -22.75 & 0.688 & -0.50 & 0.2802 & -13.25 \\
\hline $\mathbf{X}_{1}^{2}$ & 0.0005 & 38.34 & 0.0007 & 707.56 & 0.007 & 4.33 & $<0.0001$ & -91.25 \\
\hline$X_{2}^{2}$ & 0.0059 & 20.70 & 0.0775 & -252.19 & 0.024 & 3.33 & $<0.0001$ & -174.50 \\
\hline $\mathbf{X}_{3}{ }^{2}$ & 0.4943 & 48.50 & 0.0226 & -355.35 & 0.725 & -0.43 & 0.0016 & -55.25 \\
\hline
\end{tabular}
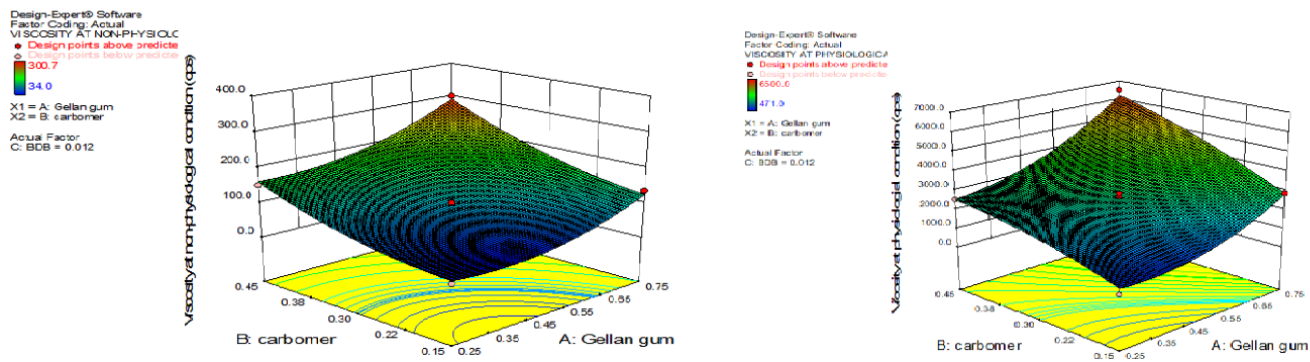

Figure 1. Response surface and Contour plots; Viscosity (cps) at the non-physiological condition $\left(25^{\circ} \mathrm{C}, \mathrm{pH} 5\right)$

$\left[\mathrm{Y}_{1}\right]$, Viscosity (cps) at the physiological condition $\left(35^{\circ} \mathrm{C}, \mathrm{pH} 7.4\right.$ and $\left.\mathrm{STF}\right)\left[\mathrm{Y}_{2}\right]$. 


\subsubsection{Statistical analysis of \% drug release at 1 hour $-\mathrm{Q} 1\left(\mathrm{Y}_{3}\right)$.}

The values obtained for $\mathrm{Q}_{1}$ for all 17 trial runs $\mathrm{O} 1-\mathrm{O} 17$ were found, ranging from $12 \%$ to $32 \%$. The outcome demonstrates that $\mathrm{Y}_{3}$ is influenced by the independent variables nominated for the examination. The response $\left(\mathrm{Y}_{3}\right)$ observed at different levels of three independent variables were exposed to manifold reversion to give a quadratic polynomial value are shown in Table 3. The non-linear model produced for $\mathrm{Q}_{1}$ was found to be significant with an F-value of 7.90, p-value 0.0062, an $\mathrm{R}^{2}$ value of 0.9104. Among the independent variables, chosen, the $\mathrm{X}_{1}$ and $\mathrm{X}_{2}$ showed negative value representing on significant effect on $\%$ drug release at 1 hour. The $\mathrm{X}_{3}$ variable has a positive value of co-efficient (0.258) representative prominent favorable effect on $\mathrm{Y}_{3}$. Out of three independent variables, the $\mathrm{X}_{1}(-1.9)$ and $\mathrm{X}_{2}(-$ 5.4) has a higher value of co-efficient. The effect of carbopol 934P Q1 is about fivefold as compared to the effect of gellan gum. This indicates that carbopol 934P, if alone used at higher concentrations, would decrease initial release to the very low content of the drug, which would be below therapeutic concentration The results are depicted in Figure 2.

\subsubsection{Statistical analysis of the time required to release $90 \%$ of drug $-\mathrm{t} 90 \%\left(\mathrm{Y}_{4}\right)$.}

The obtained values of t90\% for the 17 trial runs O1-O17 were found, ranging from 584 to 1388 minutes. The response ( $\left.\mathrm{Y}_{4}\right)$ observed at different levels of three independent variables were exposed to manifold reversion to give a quadratic polynomial value are shown in Table 3. The non-linear model produced for $t_{90} \%$ was found to be significant with an F-value of 208.4, $\mathrm{p}$-value $<0.0001$, an $\mathrm{R}^{2}$ value of 0.9962 . Out of three independent variables, $\mathrm{X}_{3}(\mathrm{BDB})$ has a negative value of co-efficient $(-25.6)$ and does not have a significant impact on sustaining the drug release. The variables $X_{1}$ and $X_{2}$ had a positive value of co-efficient $\left(X_{1}=197\right.$ and $\left.X_{2}=215\right)$ and were also found to be significant in the prediction of $\mathrm{Y}_{4}$. The results are depicted in Figure 2 .
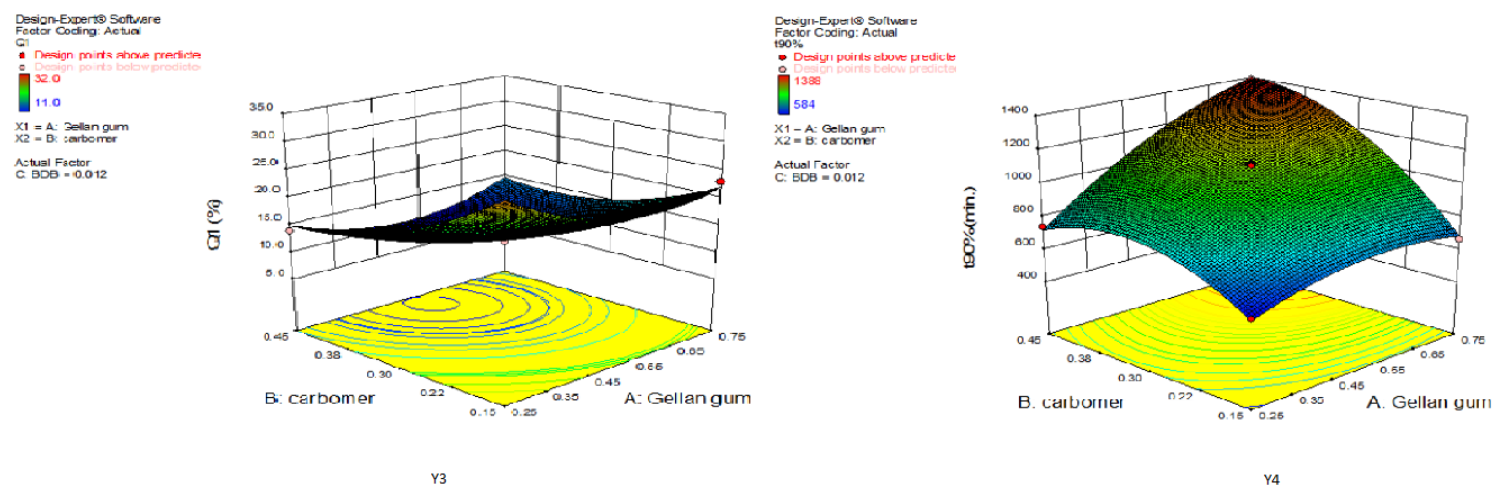

Figure 2. Response surface and Contour plots; Corrected Cumulative \% drug release at 1 hour $\left(\mathrm{Q}_{1}\right.$ in $\left.\%\right)\left[\mathrm{Y}_{3}\right]$, the time required to release $90 \%$ of drug ( $\mathrm{t}_{90 \%}$ in $\left.\min \right)\left[\mathrm{Y}_{4}\right]$

\subsubsection{Statistical analysis of Mucoadhesive strength $\left(\mathrm{Y}_{5}\right)$.}

The obtained values for mucoadhesive strength for all 17 trial runs O1-O17 were found between 9.3 to $33.3 \mathrm{gm}$. The response (Y5) observed at different levels of three independent variables were exposed to manifold reversion to give a quadratic polynomial value are shown in Table 4. The non-linear model produced for mucoadhesive strength was found to be significant with an F-value of 30.95 , p-value $<0.0001$ and $\mathrm{R}^{2}$ value of 0.9755 . Out of three independent variables, $\mathrm{X}_{3}$ has a negative value of co-efficient (-0.04), indicating an unfavorable 
response on $\mathrm{Y}_{5}$. The variable $\mathrm{X}_{1}$ and $\mathrm{X}_{2}$ havea a co-efficient value of 2.3 and 8.3, respectively. These variables showed a significant effect while $X_{2}$ represented the main causative effect on $Y_{5}$. The interaction between variable $\mathrm{X}_{1}$ and $\mathrm{X}_{2}$ had a positive value of co-efficient. Hence it can be concluded that a combination of $\mathrm{X}_{1}$ and $\mathrm{X}_{2}$ has a synergistic effect on $\mathrm{Y}_{5}$. The results are depicted in Figure 3.

Table 4. Results of regression analysis for variables of ocular in situ gelling systems $\left(\mathrm{Y}_{5}-\mathrm{Y}_{7}\right)$.

\begin{tabular}{l|c|c|c|c|c|c}
\multirow{2}{*}{$\begin{array}{l}\text { Independent } \\
\text { variables }\end{array}$} & \multicolumn{2}{|c|}{ Mucoadhesive strength $(\mathbf{G m})\left(\mathbf{Y}_{\mathbf{5}}\right)$} & \multicolumn{2}{c}{ Gel Strength(Sec) $\left(\mathbf{Y}_{\mathbf{6}}\right)$} & \multicolumn{2}{c}{ Rate of permeation $(\mathbf{c m} / \mathbf{s e c})\left(\mathbf{Y}_{\mathbf{7}}\right)$} \\
\cline { 2 - 7 } & $\mathbf{p}$ value & Coefficients & p value & Coefficients & p value & Coefficients \\
\hline Intercept & $<0.0001$ & 18.93 & 0.0001 & 28.46 & $<0.0001$ & 1.30 \\
\hline $\mathbf{X}_{\mathbf{1}}$ & 0.0041 & 2.25 & $<0.0001$ & 12.00 & 0.2749 & 0.02 \\
\hline $\mathbf{X}_{\mathbf{2}}$ & $<0.0001$ & 8.29 & 0.0167 & 2.91 & 0.6948 & 0.01 \\
\hline $\mathbf{X}_{\mathbf{3}}$ & 0.9403 & -0.04 & 0.3583 & 0.97 & $<0.0001$ & 0.42 \\
\hline $\mathbf{X}_{\mathbf{1 2}}$ & 0.1964 & 1.08 & 0.7158 & 0.50 & 0.2049 & 0.03 \\
\hline $\mathbf{X}_{\mathbf{1 3}}$ & 0.9156 & -0.08 & 0.4730 & -1.00 & 0.0903 & 0.04 \\
\hline $\mathbf{X}_{\mathbf{2 3}}$ & 1.0000 & 0.00 & 0.2070 & 1.83 & 0.2049 & -0.03 \\
\hline $\mathbf{X}_{\mathbf{1}}^{\mathbf{2}}$ & 0.1692 & -1.13 & 0.0004 & 8.10 & 0.0450 & -0.05 \\
\hline $\mathbf{X}_{\mathbf{2}}^{\mathbf{2}}$ & 0.0129 & 2.45 & 0.0220 & 3.76 & 0.0458 & -0.05 \\
\hline $\mathbf{X}_{\mathbf{3}}^{\mathbf{2}}$ & 0.0276 & -2.05 & 0.2532 & 1.60 & $<0.0001$ & -0.23
\end{tabular}

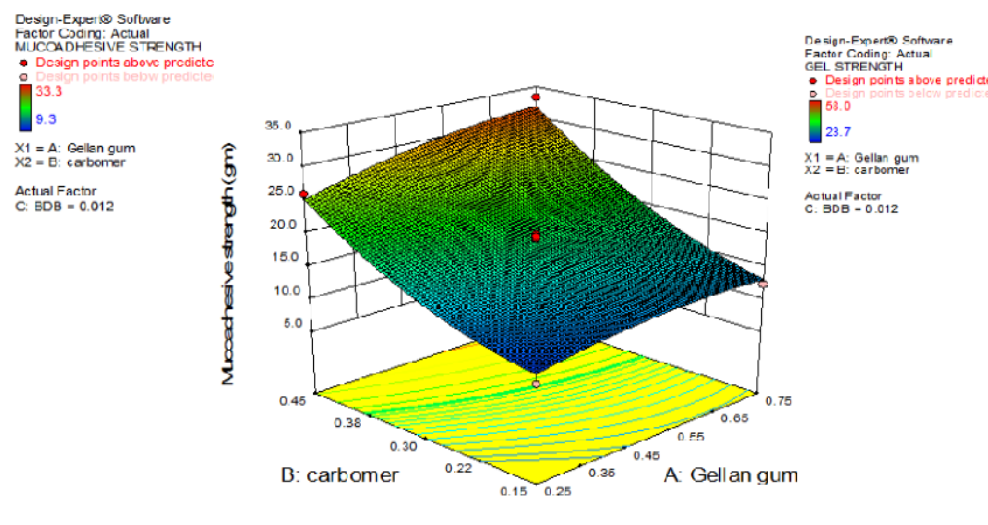

Y5

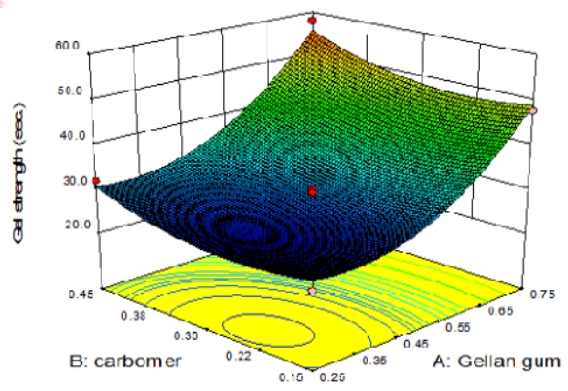

Figure 3. Response surface and Contour plots; Mucoadhesive strength $\left(\mathrm{dyn} / \mathrm{cm}_{2}\right)\left[\mathrm{Y}_{5}\right]$, Gel strength $(\mathrm{sec}).\left[\mathrm{Y}_{6}\right]$.

3.1.6. Statistical analysis of Gel strength $\left(\mathrm{Y}_{6}\right)$.

The obtained values for gel strength for all 17 trial runs O1-O17 were found between from 23 to 58 seconds. The response ( $\mathrm{Y}_{6}$ ) observed at different levels of three independent variables were exposed to multiple reversion to give a quadratic polynomial value are shown in Table 4. The non-linear model produced for gel strength was found to be significant with an F-value of 25.83, p-value $<0.0001$, an $\mathrm{R}^{2}$ value of 0.9707 . None of the independent variables had a negative value of co-efficient, indicating a favorable effect on $\mathrm{Y}_{6}$. The variable $\mathrm{X}_{1}$ and $\mathrm{X}_{2}$ have a co-efficient value of 12 and 2.9, respectively. These variables were also found to be noteworthy, representing the main causative result of $\mathrm{X}_{1}$ on $\mathrm{Y}_{6}$. The results are depicted in Figure 3.

3.1.7. Statistical analysis of the permeability coefficient $\left(\mathrm{Y}_{7}\right)$.

The obtained values for the permeability coefficient for all 17 trial runs $\mathrm{O} 1-\mathrm{O} 17$ were found between from 0.56 to 1.46 (x $10^{-5} \mathrm{~cm} / \mathrm{sec}$.). The response $\left(\mathrm{Y}_{7}\right)$ observed at different levels of three independent variables were subjected to manifold reversion to give a quadratic polynomial value, as shown in Table4. The non-linear model produced for the permeability 
coefficient was found to be significant with an F-value of 107.73, p-value $<0.0001$, an $\mathrm{R}^{2}$ value of 0.9928 . None of the independent variables had a negative value of co-efficient. The coefficient value $X_{1}$ and $X_{2}$ were very low 0.01 and 0.006 , respectively, representing a negligible effect on $\mathrm{Y}_{7}$. These two variables were found insignificant The variable $\mathrm{X}_{3}$ Benzododecinium bromide was found to be significant with a coefficient value of 0.42 representing the main causative effect of $\mathrm{X}_{3}$ on $\mathrm{Y}_{7}$. Thus benzododecenium bromide act as a trans-corneal permeation enhancer to improve corneal permeability of prepared in situ gelling trial runs. The results are depicted in Figure 4.

Results shown in Table 5 suggested that there is wide variability in values obtained for each response of formulations. It shows higher values of standard deviation (SD) and \% coefficient of variation (CV). These results show that the chosen independent variable meaningfully affected independent variables. The good $\mathrm{R}^{2}$ values $(>0.91)$ indicate a good correlation between the independent and dependent variables selected for the study.

Table 5. Results of regression analysis for responses of ocular in situ gelling systems.

\begin{tabular}{l|l|l|l} 
Response/Dependent Variable & $\mathbf{R}^{\mathbf{2}}$ & SD & \% CV \\
\hline $\mathrm{Y}_{1}=$ Viscosity at Non Physiological condition $\left(25^{\circ} \mathrm{C}\right.$ and $\left.\mathrm{pH} 5\right)$ & 0.9846 & 12.78 & 10.65 \\
\hline $\mathrm{Y}_{2}=$ Viscosity at physiological condition $\left(35^{\circ} \mathrm{C}\right.$ and $\left.\mathrm{pH} 7.4\right)$ & 0.9870 & 250.31 & 9.32 \\
\hline $\mathrm{Y}_{3}=$ Corrected Cumulative \% drug release at 1 hour $\left(\mathrm{Q}_{1}\right.$ in $\left.\%\right)$ & 0.9104 & 2.39 & 14.93 \\
\hline $\mathrm{Y}_{4}=$ Time required to release $90 \%$ of drug $\left(\mathrm{t}_{90}\right.$ in $\left.\mathrm{min}\right)$ & 0.9963 & 22.64 & 2.36 \\
\hline $\mathrm{Y}_{5}=$ Mucoadhesive Strength $(\mathrm{gm})$ & 0.9755 & 1.52 & 8.16 \\
\hline $\mathrm{Y}_{6}=$ Gel strength $(\mathrm{sec})$. & 0.9707 & 2.63 & 7.58 \\
\hline $\mathrm{Y}_{7}=$ rate of Permeability/Permeability coefficient $(\mathrm{cm} / \mathrm{sec})$. & 0.9928 & 0.04 & 3.64
\end{tabular}

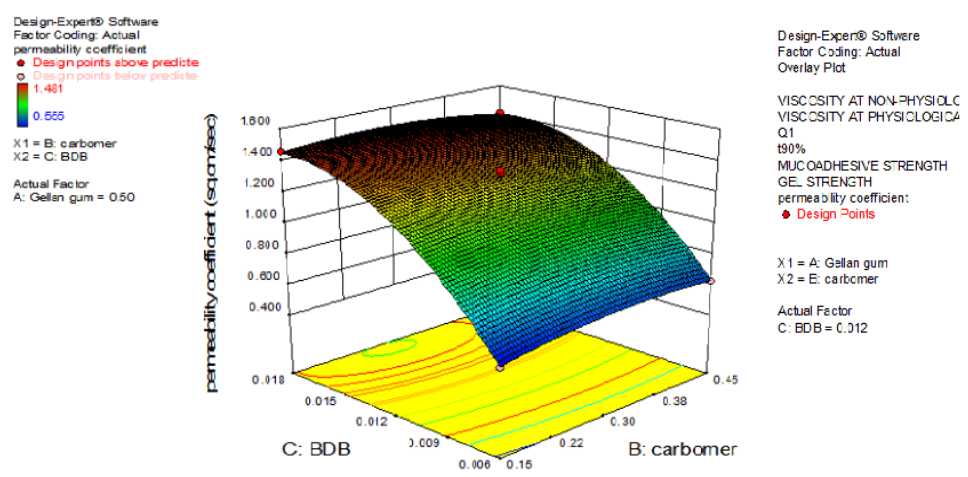

Y7

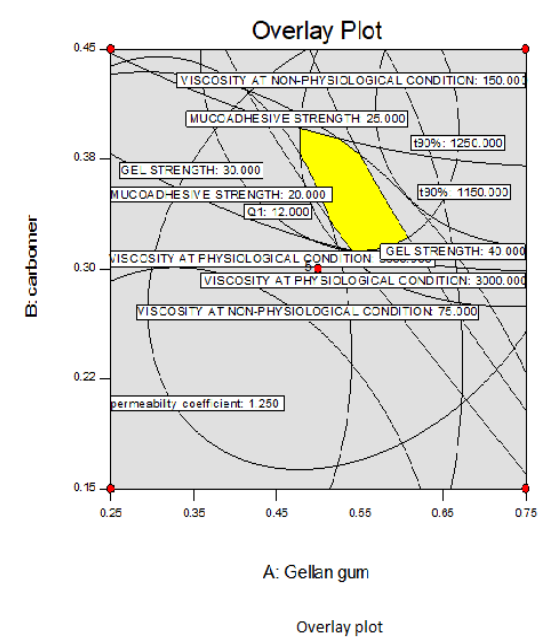

Overlay plot

Figure 4. Response surface and Contour plot for Rate of Permeability/Permeability coefficient (cm/sec.) $\left[\mathrm{Y}_{7}\right]$ and Overlay Plot for all possible sets of variables.

\subsection{Contour plots and response surface analysis.}

The impact of independent variables on the response was further explained utilizing the contour plots. It was decided from the 3D surface plot that the desired non-physiological viscosity is 75 to $125 \mathrm{cps}$ for ease of installation. It may be accomplished by an increase in the concentration of carbopol 934P. The viscosity remained at $125 \mathrm{cps}$ at a concentration of carbopol $934 \mathrm{P}$ at $0.15 \%$ and of gellan gum at $0.45 \%$.

The 3D surface plot (Figure 1) shows the impact of viscosity, which is due to phase transition from sol to gel at the physiological condition. The highest value of viscosity could be obtained at a higher concentration of both polymers. However, the desired viscosity range of $\mathrm{Y}_{2}$ is 3200 to $3600 \mathrm{cps}$. The increase in viscosity at physiological conditions is directly 
proportional to the increase in the concentration of gellan gum. Hence the lines in contour plots are inclining towards the right side. The desired value of Y2 could be obtained in an area of $0.25-0.4 \%$ carbopol $934 \mathrm{P}$ and $0.4-0.7 \%$ gellan gum. The desirable value of cumulative $\%$ drug release at 1 hour is $10-12 \%$, which could be observed in the region of $0.3-0.45 \%$ carbopol $934 \mathrm{P}$ and $0.2-0.65 \%$ gellan gum.

The 3D surface plot (Figure2) also shows the prominent effect of gellan gum concentration (X1), carbopol 934P concentration $\left(\mathrm{X}_{2}\right)$, and $\mathrm{BDB}$ concentration $\left(\mathrm{X}_{3}\right)$ on time required for $90 \%$ release of Timolol maleate $\left(\mathrm{Y}_{4}\right)$. The optimum value of t90\% is 1200 to 1250 minutes, which can be obtained by selecting $0.23-0.45 \%$ of carbopol $934 \mathrm{P}$ and $0.4-0.75 \%$ of gellan gum, respectively.

Benzododecenium bromide $\left(\mathrm{X}_{3}\right)$ has been utilized as a preservative, and its permeability enhancement effect has been seen with non-linear curvature along with carbopol 934P $\left(\mathrm{X}_{2}\right)$. The mucoadhesive target strength (22 to $25 \mathrm{gm}$ ) effect can be attained in an area of $0.31-0.37 \%$ carbopol 934P and 0.55-0.67\% gellan gum.

The high value of gel strength (35 to $40 \mathrm{sec}$ ) in an area of $0.15-0.40 \%$ carbopol $934 \mathrm{P}$ and $0.50-0.65 \%$ gellan gum. The plots clearly reflect that as the concentration of gellan gum rises with the value of gel strength (Figure 3).

The 3D surface plot Figure 4 shows the effect of factor gellan gum $\left(\mathrm{X}_{1}\right)$ and BDB $\left(\mathrm{X}_{3}\right)$ on the permeability coefficient $\left(\mathrm{Y}_{7}\right)$. The plots clearly show that as the concentration of BDB increases, the value of permeability also increases. There is more contributing effect of BDB. The desired value of $\mathrm{Y}_{7}(1.250$ to $1.450 \mathrm{sq} . \mathrm{cm} / \mathrm{sec})$ could be obtained with $0.011-0.015 \%$ of BDB.

\subsection{Validation of response surface methodology.}

To validate the Box Behnken Design model, three checkpoint batches were prepared and evaluated. The composition of checkpoint batches with predicted and experimental values are shown in Table 6. The prediction error of the predicted values from the experimental values varied between -8.33 and +7.69 . The experimental values of viscosity (cps) at the non-

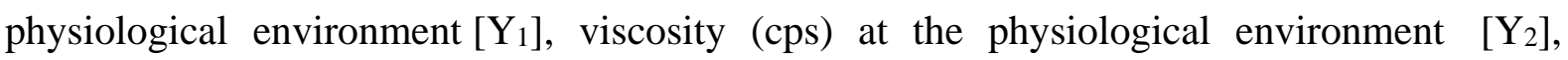
Corrected Cumulative $\%$ drug release at 1 hour [ $\mathrm{Y}_{3}$ ] Time required to release $90 \%$ of drug[ $\left.\mathrm{Y}_{4}\right]$,

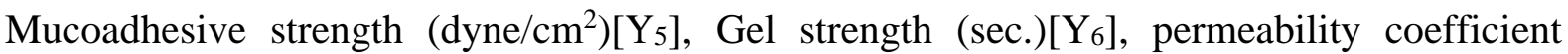
$\left(\mathrm{cm} / \mathrm{sec}\right.$. [Y $_{7}$ ] were found to be $123 \pm 8 \mathrm{cps}, 3300 \pm 90 \mathrm{cps}, 11 \pm 0.5,1220$ minutes, $23 \pm 2 \mathrm{dyne} / \mathrm{cm}^{2}$, $37 \pm 2$ and $1.350 \mathrm{sq} . \mathrm{cm} / \mathrm{sec}$. respectively, which are in close accordance with the predicted response by model. Thus, the preferred Box Behnken Design model was found fit and validated. It can be utilized for the optimization of the in-situ gelling system.

Table 6. Validation results of response surface methodology with checkpoint batches.

\begin{tabular}{l|l|l|l|l}
$\begin{array}{l}\text { Checkpoint batch composition } \\
\left(\mathbf{X}_{1}: \mathbf{X}_{2}: \mathbf{X}_{3}\right)\end{array}$ & Response variable & Experimental value & Predicted value & \% prediction error \\
\hline $0.37: 0.23: 0.012$ & Y1 & 48 & 51 & -6.25 \\
$(-0.52:-0.46: 0)$ & Y2 & 1612 & 1525 & 5.39 \\
& Y3 & 18 & 18.4 & -2.22 \\
& Y4 & 870 & 878 & -0.91 \\
& Y5 & 15 & 14.4 & 4 \\
& Y6 & 26 & 24 & 7.69 \\
& Y7 & 1.260 & 1.267 & 0 \\
\hline $0.62: 0.38: 0.018$ & Y1 & 160 & 173 & -8.12 \\
$(0.48: 0.53: 1)$ & Y2 & 4090 & 3982 & 2.64 \\
& Y3 & 11 & 11 & 0 \\
& Y4 & 1180 & 1235 & -4.66 \\
& Y5 & 25 & 24 & 4
\end{tabular}




\begin{tabular}{l|l|l|l|l}
\hline $\begin{array}{l}\text { Checkpoint batch composition } \\
\left(\mathbf{X}_{1}: \mathbf{X}_{2}: \mathbf{X}_{3}\right)\end{array}$ & Response variable & Experimental value & Predicted value & \% prediction error \\
\hline & Y6 & 42 & 41 & 2.3 \\
& Y7 & 1.460 & 1.476 & -1.09 \\
\hline $0.37: 0.38: 0.006$ & Y1 & 108 & 114 & -5.55 \\
$(-0.52: 0.53:-1)$ & Y2 & 2320 & 2258 & 2.67 \\
& Y3 & 11 & 12 & -8.33 \\
& Y4 & 985 & 1005 & -2.03 \\
& Y5 & 20 & 21 & -5 \\
& Y6 & 27 & 26 & 3.7 \\
& Y7 & 0.645 & 0.641 & 0.6 \\
\hline $0.62: 0.23: 0.012$ & Y1 & 92 & 96 & -4.3 \\
$(.48:-0.46: 0)$ & Y2 & 2820 & 2748 & 2.55 \\
& Y3 & 15 & 16 & -6.66 \\
& Y4 & 1030 & 1014 & 1.55 \\
& Y5 & 15 & 16 & -6.66 \\
& Y6 & 37 & 35 & 5.4 \\
& Y7 & 1.270 & 1.273 & -0.23 \\
\hline $0.3: 0.2: 0.015$ & Y1 & 39 & 42 & -7.69 \\
$(-0.8:-0.6:+0.5)$ & Y2 & 1165 & 1104 & 5.2 \\
& Y3 & 24 & 23 & 4.1 \\
& Y4 & 750 & 715 & 4.66 \\
& Y5 & 13 & 12 & 7.6 \\
& Y6 & 27 & 25 & 7.4 \\
& Y7 & 1.383 & 1.383 & 0
\end{tabular}

\subsection{Optimization.}

The experimental design, statistical analysis, and overlaying contour plot (Figure 4) revealed the optimal formulation composition, as shown in Table 7. This formula is expected to satisfy the most extreme essentials, considering the applied constraints on $\mathrm{Y}_{1}$ to $\mathrm{Y}_{7}$. The software suggested optimal formula is expected to give $99 \%$ desirability with predicted nonphysiologic viscosity of $123 \pm 8 \mathrm{cps}$, physiological viscosity of $3300 \pm 90 \mathrm{cps}$, cumulative $\%$ drug release at 1 hour $\left(\mathrm{Q}_{1}\right)$ of $11 \pm 0.5 \%$, time to release $90 \%$ of drug ( $\left.\mathrm{t}_{90}\right)$ of 1220 minutes, mucoadhesive strength of $23 \pm 2 \mathrm{dyne} / \mathrm{cm}^{2}$, gel strength of $37 \pm 2$ seconds and permeability coefficient of $1.350 \mathrm{sq} . \mathrm{cm} / \mathrm{sec}$. The optimized batch was prepared and evaluated. The results are discussed in the subsequent section.

Table 7.Optimized formulation composition.

\begin{tabular}{l|l|l} 
Sr. No. & Ingredient & Quantity $(\% \mathbf{w} / \mathbf{v})$ \\
\hline 1 & Timolol maleate & 0.50 \\
\hline 2 & Gellan gum & 0.48 \\
\hline 3 & Carbopol 934P & 0.37 \\
\hline 4 & Benzododecinium bromide & 0.012 \\
\hline 5 & Mannitol & 5.30 \\
\hline 6 & Double distilled deionized water q.s. to & 100
\end{tabular}

\subsection{Evaluation of optimized in-situ gel.}

\subsubsection{In-vitro drug release study.}

The drug release profile after sol to gel transformation of in situ gelling showed linearity with the square root of time and followed 'Higuchi's equation. The transport technique was the same as obtained by the Korsmeyer- Peppas exponential Equation. It was moreover observed that 'Higuchi's plot and Peppas plot were more linear relative to zero-order and first-order plot. Hence these two model-dependent methods were considered for a deriving conclusion. The correlation coefficient $\left(\mathrm{R}^{2}>0.97\right)$ was obtained with 'Higuchi's law representing that release from the formulation is based on a diffusion method for all ion-sensitive in situ ocular gelling systems. The release was found by Fickian $(n<0.5)$ as well as non-Fickian $(n>0.5)$ diffusion 
method as interpreted from the value of release exponent obtained from kinetic release data. The drug release profile of optimized formulation shows linear drug release, as shown in Figure 5. The drug release was found similar to marketed formulation with fewer fluctuations in $\%$ drug release.

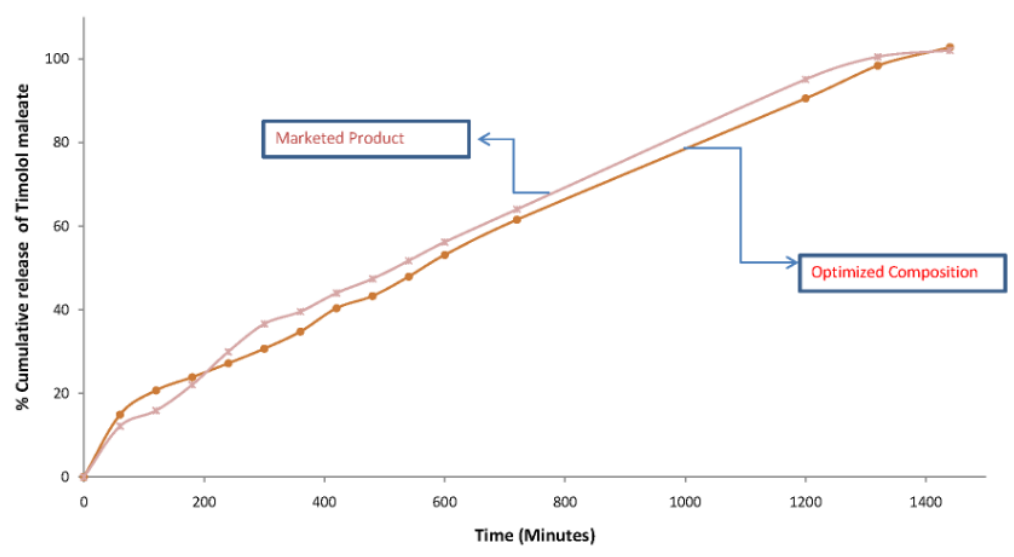

Figure 5. The comparative in-vitro drug release profile of optimized formulation with marketed Product.

3.5.2. In- vitro trans-corneal permeation study.

Trans-corneal penetration is believed to be the major route for ocular drug absorption. The quantity of the drug absorbed through the cornea can be optimized by controlling the drug release rate from polymer matrix and/or by decreasing drug loss through tear drainage and conjunctival absorption. Both tear drainage and diffusion across the conjunctiva are responsible for drug loss in the precorneal area. The rate of solution drainage decreases with higher viscosity and mucoadhesiveness. Drug diffusion across the conjunctiva is also another factor for drug loss. Hence, for the optimum drug absorption through the cornea, the drug release rate should be controlled along with the decrease in drug loss.

From optimization studies, it was clear that the drug permeation increases with a higher concentration of Benzododecinium bromide. From the Box Behnken design, the predicted value of the permeability coefficient was between $1.25-1.45 \mathrm{sq} . \mathrm{cm} / \mathrm{sec}$, while the experimental value was found out to be $1.35 \mathrm{sq} . \mathrm{cm} / \mathrm{sec}$ for the optimized formulation, i.e., well within the desired range. Thus it can be said that the optimized formulation provides optimum transcorneal permeation of the drug. The result is shown in Table 8.

Table 8. Characterization of the optimized formulation.

\begin{tabular}{|c|c|c|c|}
\hline Sr.No. & Dependent variables & Predicted values & Experimental values \\
\hline 1 & $\begin{array}{l}\mathrm{Y}_{1}=\text { Viscosity (cps) at non-physiological condition } \\
\left(25^{\circ} \mathrm{C} \text { and } \mathrm{pH} 5\right)\end{array}$ & $\mathrm{Y}_{1}=75$ to $125 \mathrm{cps}$ & $123 \pm 8$ \\
\hline 2 & $\begin{array}{l}\mathrm{Y}_{2}=\text { Viscosity (cps) at physiological condition } \\
\left(35^{\circ} \mathrm{C} \text { and } \mathrm{pH} 7.4\right)\end{array}$ & $\mathrm{Y}_{2}=3200$ to $3600 \mathrm{cps}$ & $3300 \pm 90$ \\
\hline 3 & $\mathrm{Y}_{3}=$ Cumulative $\%$ drug release at 1 hour $\left(\mathrm{Q}_{1}\right.$ in $\left.\%\right)$ & $\mathrm{Y}_{3}=10$ to $12 \%$ & $11 \pm 0.5$ \\
\hline 4 & $\begin{array}{l}Y_{4}=\text { Time required to release } 90 \% \text { of drug }\left(t_{90} \text { in }\right. \\
\text { min) }\end{array}$ & $\mathrm{Y}_{4}=1200$ to 1250 minutes & 1220 \\
\hline 5 & $\mathrm{Y}_{5}=$ Mucoadhesive strength $(\mathrm{gm})$ & $\mathrm{Y}_{5}=22$ to $25 \mathrm{gm}$ & $23 \pm 2$ \\
\hline 6 & $\mathrm{Y}_{6}=$ Gel strength $(\mathrm{sec})$. & $\mathrm{Y}_{6}=35$ to 40 seconds. & $37 \pm 2$ \\
\hline \multirow[t]{2}{*}{7} & $\begin{array}{l}Y_{7}=\text { rate of Permeability/Permeability coefficient } \\
\text { (sq.cm/sec.) }\end{array}$ & $\mathrm{Y}_{7}=1.250$ to $1.450 \mathrm{sq} . \mathrm{cm} / \mathrm{sec}$ & 1.350 \\
\hline & Other evaluation parameters & \multicolumn{2}{|l|}{ Experimental values } \\
\hline 8 & Appearance & \multicolumn{2}{|l|}{ Clear } \\
\hline 9 & Clarity $(\%)$ & \multicolumn{2}{|l|}{97} \\
\hline 10 & $\mathrm{pH}$ & \multicolumn{2}{|l|}{5.8} \\
\hline \multirow[t]{2}{*}{11} & In-vitro gelling capacity - by flowability & \multicolumn{2}{|l|}{ 5-10 seconds } \\
\hline & In-vitro gelling capacity - by visual method & \multicolumn{2}{|l|}{+++} \\
\hline \multicolumn{2}{|c|}{ https://biointerfaceresearch.com/ } & & 825 \\
\hline
\end{tabular}




\subsubsection{Rheological study.}

The viscosity of the optimized formulation was measured in physiological and nonphysiological conditions. A significant increase in viscosity was observed of optimized formulation at physiological conditions $\left(37^{\circ} \mathrm{C} \mathrm{pH} 7.4\right)$ in the presence of simulated tear fluid. Figure 6 shows the viscosity versus angular velocity (RPM) flow curves of optimized formulation and marketed formulation at non-physiological and physiological conditions, respectively. Both formulations show shear-thinning pseudoplastic rheological behavior, which will allow uniform distribution of the formulation across the eye surface. The viscosity under physiological conditions was much higher compared to non-physiological conditions suggesting the phase transition from sol to gel. In the present investigation, the approach is to achieve the optimal viscosity by mixing carbopol 934P with gellan gum. When the nonphysiological condition was changed into physiological condition with a $\mathrm{pH} 4-5$ to 7.4 in the presence of cations, the viscosity of optimized formulation had a significant increase. This can be owing to the ion-sensitive gelling property of gellan gum.
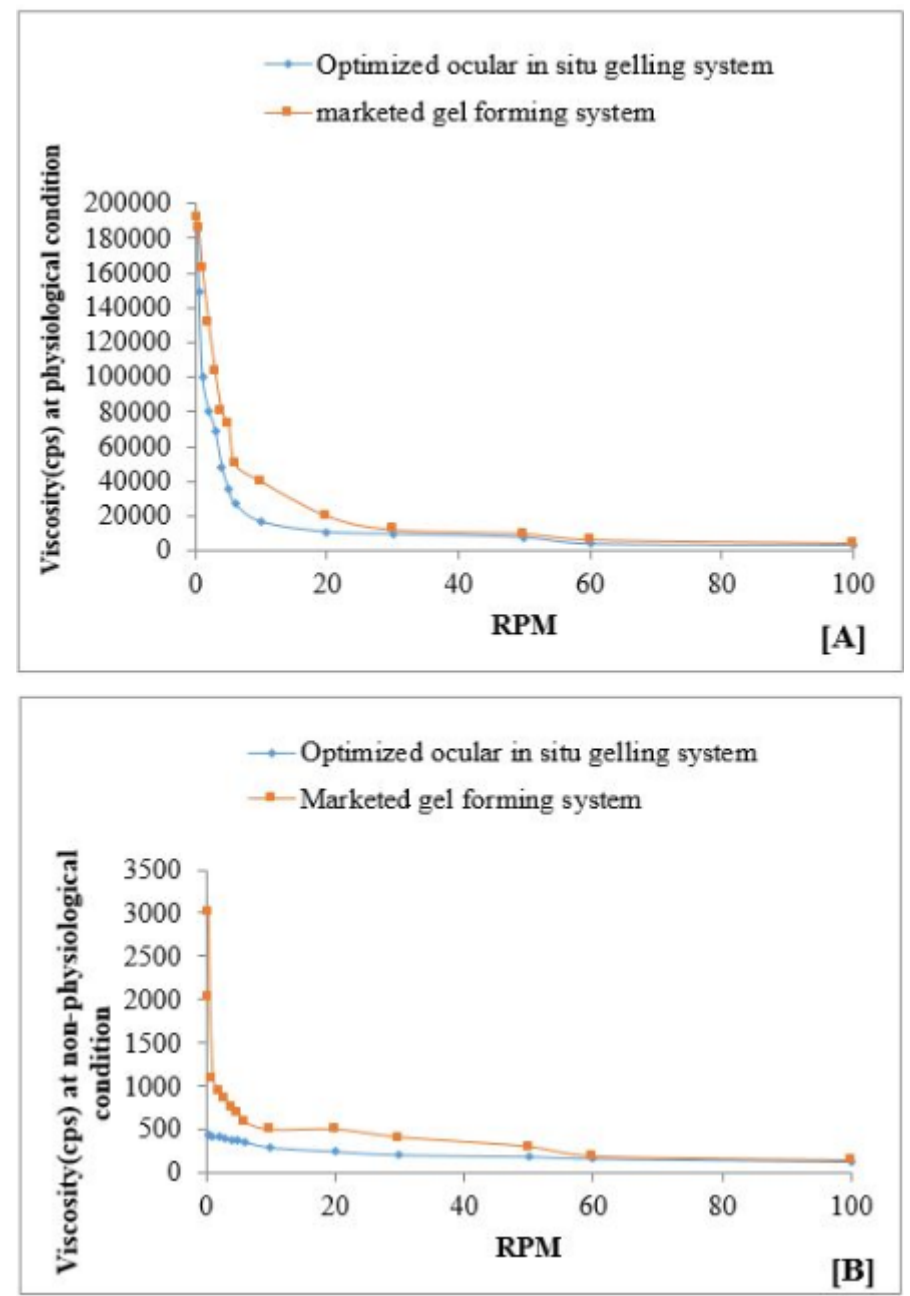

Figure 6. Rheological study at [A] Physiological condition [B] non-physiological condition.

Carbopol 934P shows a mucoadhesive and a $\mathrm{pH}$-sensitive in situ gelling property and forms a stiff gel when the $\mathrm{pH}$ was raised above its pka value due to the increase in ionization. This leads to an increase in electrostatic repulsion between adjacent carboxyl groups and the subsequent expansion of the polymer network. The cross-linking between carbopol 934P with gellan gum may result in the formation of more viscous gel at the physiological conditions. The combined polymer solution may have enough strength to withstand the turnover and 
provide a long precorneal residence time. This also shows that without increasing the concentration of individual polymer solution, the mixed vehicle may be administrated as eye drops and form stronger gel following the phase transition in the ocular cul-de-sac of the eye.

From the optimizations study, the predicted viscosity at non-physiological conditions was between 75-125 cps, while the viscosity of the optimized formulation was found to be 123 cps. Similarly, the viscosity at physiological condition was predicted to be 3200-3600 cps, and experimentally it was found to be $3300 \mathrm{cps}$ for the optimized formulation. The results are shown in Table 8.

\subsubsection{Clarity test and $\mathrm{pH}$.}

During the clarity testing, the optimized formulation was found clear and transparent visually, which shows the ease of application for treatment in day time use without affecting any visual acuity. The clarity doesn't get affected by the sterilization process. The result of clarity in the form of \% Transmittance is shown in Table 8.

The $\mathrm{pH}$ of optimized formulation was obtained between the desired $\mathrm{pH}$ range of 5.5 and 5.8. The formulation was a clear transparent, free-flowing solution at the set range of $\mathrm{pH}$ when formulated. The result is shown in Table 8 . Since the $\mathrm{pH}$ of the optimized formulation was found within an acceptable range, the formulation would not create irritation but will be well tolerated within the eye. The sterilization process doesn't show any effect on the $\mathrm{pH}$ of the formulation.

\subsubsection{In-vitro gelling capacity.}

Gelling capacity is one of the most important requirements of in situ gelling formulations. The optimum viscosity of the formulation allows easy administration and rapid sol-gel transition at the physiological condition. The gelling capacity of optimized formulation was evaluated on the basis of flowability and visual evaluation of gel stiffness and its retention time. We assessed the gel capacity on a grading scale between - and ++++ . The grades of gelation were recorded as: (-) No gelation, (+) weak gelation remains up to $10 \mathrm{~min},(++)$ Immediate gelation remains for up to $5 \mathrm{hrs}$ (less stiff gel), $(+++)$ Immediate gelation remains for longer period up to $10 \mathrm{hrs}$ (stiff gel) $(++++)$ Immediate gelation remains for extended period for more than $12 \mathrm{hrs}$ (Very stiff gel).

The results showed in Table 8indicate the in-vitro gelling capacity of the optimized formulation by means of flowability and visual gelling observation. The authors could not see any change in flowability due to temperature change. The good flow at various temperatures shows the ease of installation in the eye and no gelling in the non-physiological state. However, during the physiological condition in the visual method, the optimized formulation showed immediate gelation within a period of 5-10 seconds. This short gelation time indicates that the formulation will not get drained due to eyelid blinking.

\subsubsection{Isotonicity.}

The results observed from isotonicity study are depicted in Figure 7. It was observed that the size of RBCs remained unchanged during the exposure with the optimized formulation and was found comparable with the exposure to the normal saline solution $(0.9 \%$ sodium chloride). The results from the Isotonicity study shows that the optimized formulation is 
isotonic with the physiological fluids, and the formulation will not cause any discomfort like irritation or inflammation in the eye.

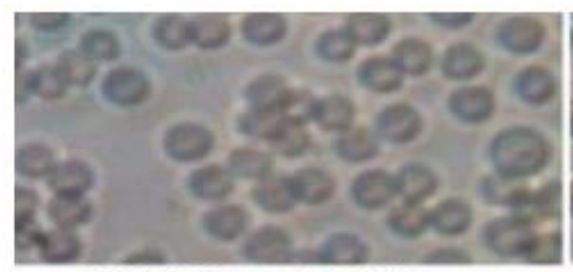

RBC in Hypotonic Solution

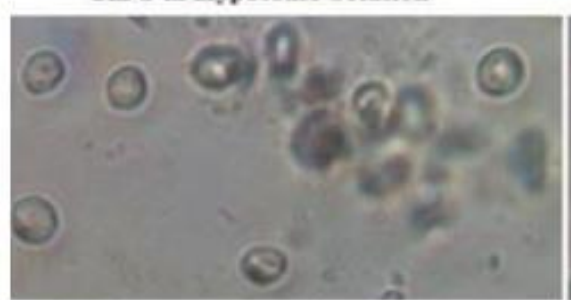

RBC in Normal Saline

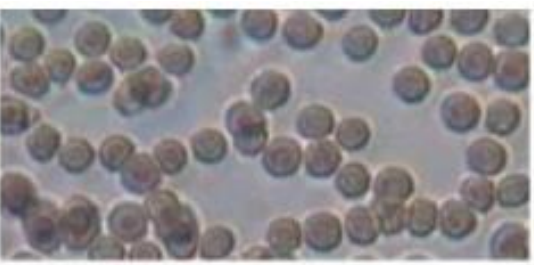

RBC in Hypertonic Solution

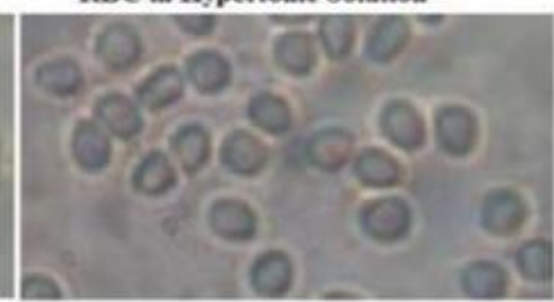

RBC in Formulation

Figure 7. Isotonicity Study at $0.9 \%$ Saline at 60x magnification.

\subsubsection{Measurement of texture analysis.}

Texture profile analysis (TPA) characterizes the mechanical parameters like Gel strength (hardness), mucoadhesion force, gel rupture force, the force of adhesion, compressibility, and adhesiveness. The TPA graph and calculated mechanical properties of the ocular in situ gelling system are presented in Figure 8 and Table 9, respectively. The outcome of texture analysis confirms that Timolol maleate formulation had appropriate mechanical belongings for ophthalmic administration [22].

Table 9. Mechanical properties of ocular in situ gelling system.

\begin{tabular}{l|l|l} 
Sr. No. & Parameter & Result \\
\hline 1 & Gel Strength (hardness) & $50798 \mathrm{gm}$ \\
\hline 2 & Adhesive/Mucoadhesion Force & $-73.60 \mathrm{gm}$ \\
\hline 3 & Gel Rupture & $50798 \mathrm{gm}$ \\
\hline 4 & Force of adhesion & $0.7310 \mathrm{~N}$ \\
\hline 5 & Compressibility (AUC) & 63748 \\
\hline 6 & Adhesiveness & $-57.46 \mathrm{gm}$
\end{tabular}

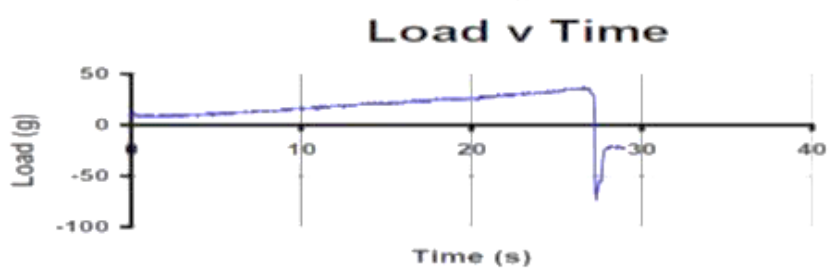

[A]

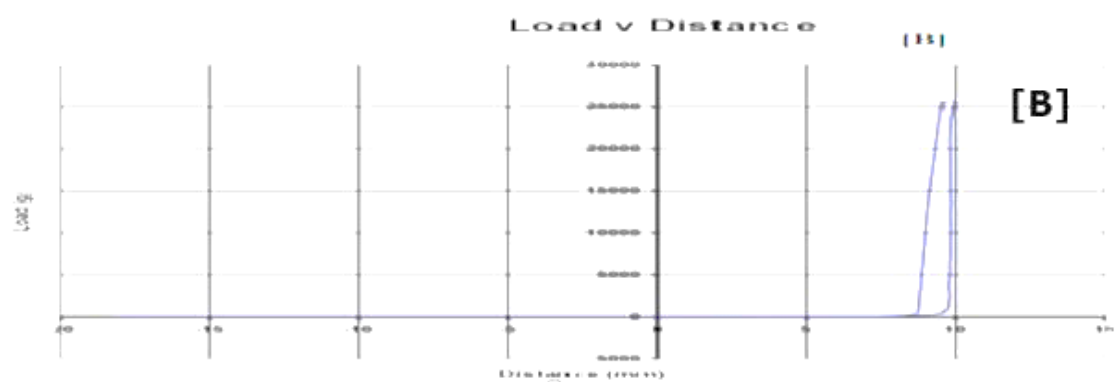

Figure 8. (A) TPA force-time plot of ocular in situ gelling system and (B) TPA force-distance plot of ocular in situ gelling system. 
3.5.8. Measurement of contact angle.

Lower contact angle indicates ease of application and spreading on the ocular surface. The contact angle of the optimized formulation was found significantly lower compared to the marketed gel-forming system. The value of the contact angle on the hydrophilic surface was found to be lower than obtained on the hydrophobic surface. It can be interpreted from the result that the additional polymer in optimized formulation compared to marketed formulation would reduce the contact angle by reducing the surface tension. Hence it can be anticipated that the optimized formulation would give better spreading across the corneal surface compared to a marketed formulation, which would also enhance the permeation of drugs across cornea [26]. The results are shown in Table 10.

Table 10.Contact angle comparison of optimized formulation with marketed formulation.

\begin{tabular}{|c|c|c|c|}
\hline Sr. No. & Sample details & Measurement surface & Average Contact Angle $(\theta) \pm$ S.D. \\
\hline \multirow[t]{2}{*}{1} & \multirow{2}{*}{ Optimized in situ gelling formulation } & Hydrophilic surface & $24.6 \pm 3.6$ \\
\hline & & Hydrophobic surface & $92.19 \pm 2.8$ \\
\hline \multirow[t]{2}{*}{2} & \multirow[t]{2}{*}{ Marketed formulation } & Hydrophilic surface & $34.2 \pm 6.1$ \\
\hline & & Hydrophobic surface & $76.25 \pm 5.4$ \\
\hline
\end{tabular}

\subsubsection{Histopathological evaluation of cornea.}

The microscopic observation of corneal structure after incubation with the optimized formulation is shown in Figure 9. It was observed that the epithelium film appeared unbroken and proper without any sign of inflammation and doesn't show any difference with the Phosphate buffer saline-treated cornea. Therefore, it is safe to administer the optimized formulation in the eye. It also shows that benzododecinium bromide is a safe alternative for the prevention of corneal damage compared to other conventional preservatives like benzalkonium chloride.

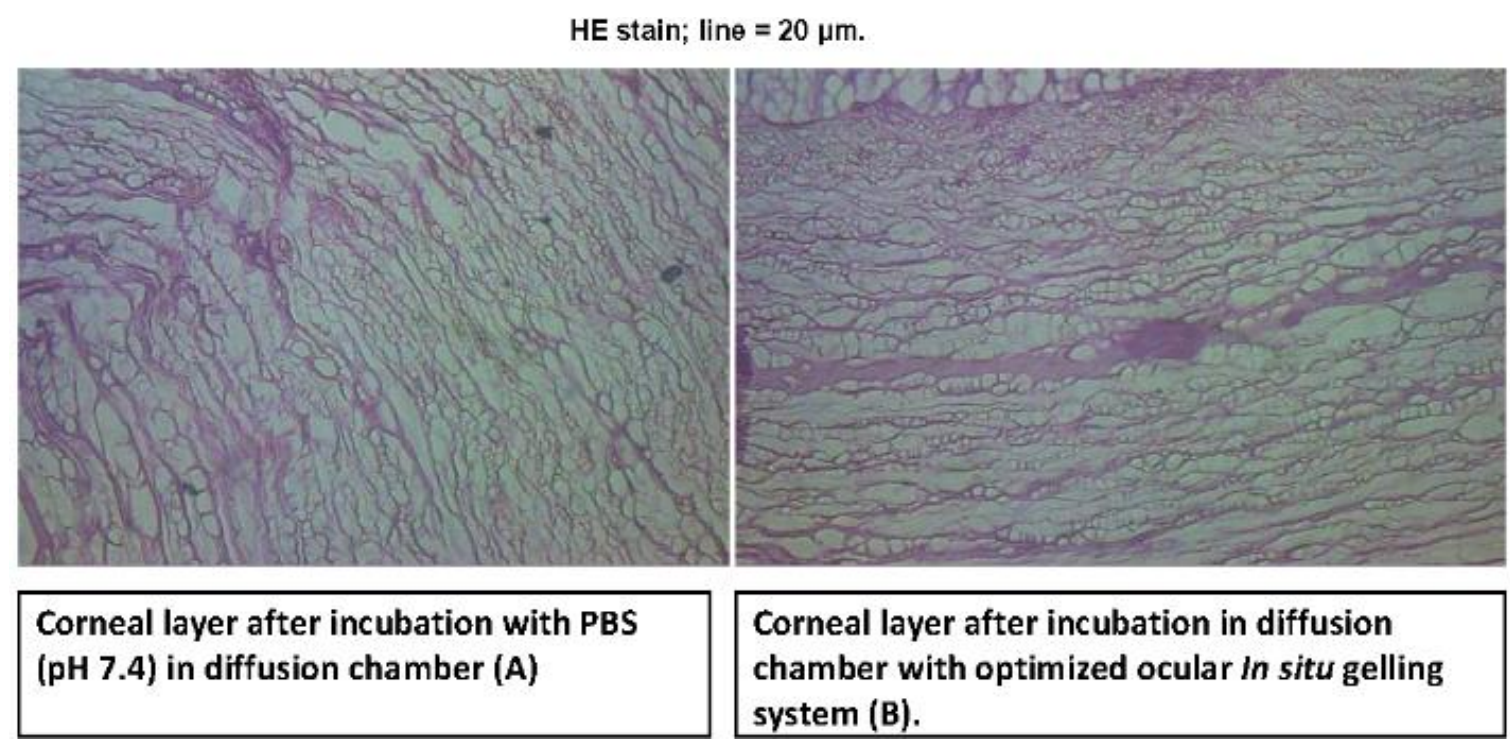

Figure 9. Histopathological evaluation of cornea.

\subsubsection{Sterility test.}

Sterility testing revealed that there was neither growth nor any evidence of turbidity observed in both media incubated for 14 days. Results assured the sterility of the optimized formulation, and the appropriateness of the sterilization method followed [28]. 


\subsubsection{Antimicrobial effectiveness test.}

The selected preservative for optimized formulation should have effectiveness to resist the growth of organisms during the entire shelf life and up to the end-use of the patient. The diameter of the zone of inhibition is shown in Table 11. The Zone of Inhibition (ZOI) values for the optimized in situ gelling systems were either similar or higher than the ZOI values of the marketed preparation. Also, the ZOI values against $S$. aureus were found higher than that against E.coli. The comparable ZOI values of the optimized formulation with the marketed formulation are due to the prolonged diffusion of the preservative, i.e., benzododedecinum bromide from the in situ gelling system due to its higher viscosity. The results also suggest the effectiveness of benzododecinium bromide against the micro-organisms under study [29].

Table 11. Antimicrobial efficacy of in situ gelling systems against E.Coli \& S.Aureus.

\begin{tabular}{|c|c|c|c|c|c|c|c|}
\hline \multirow[t]{3}{*}{ Sr. No. } & \multirow{3}{*}{$\begin{array}{l}\text { Concentration } \\
\quad(\mu \mathrm{g} / \mathrm{ml})\end{array}$} & \multicolumn{4}{|c|}{ Zone of Inhibition $(\mathrm{cm})$} & \multirow{2}{*}{\multicolumn{2}{|c|}{$\begin{array}{c}\text { Percentage efficiency }(\%) \\
\text { Optimized in situ gelling system }\end{array}$}} \\
\hline & & \multicolumn{2}{|c|}{ Marketed formulation } & \multicolumn{2}{|c|}{$\begin{array}{c}\text { Optimized in situ gelling } \\
\text { system }\end{array}$} & & \\
\hline & & $\begin{array}{c}\text { After } 18 \\
\text { hours }\end{array}$ & $\begin{array}{c}\text { After } 24 \\
\text { hours }\end{array}$ & $\begin{array}{c}\text { After } 18 \\
\text { hours }\end{array}$ & $\begin{array}{c}\text { After } 24 \\
\text { hours }\end{array}$ & $\begin{array}{c}\text { After } 18 \\
\text { hours }\end{array}$ & After 24 hours \\
\hline \multicolumn{8}{|c|}{ (A) E.Coli } \\
\hline 1 & 5 & $16 \pm 0.54$ & $19 \pm 1.0$ & $16 \pm 1.0$ & $24 \pm 0.0$ & 100 & 126.3 \\
\hline 2 & 10 & $18 \pm 0.54$ & $21 \pm 1.0$ & $18 \pm 0.54$ & $24 \pm 0.54$ & 100 & 114.3 \\
\hline 3 & 30 & $21 \pm 1.0$ & $22 \pm 1.0$ & $21 \pm 0.44$ & $24 \pm 1.0$ & 100 & 109.0 \\
\hline
\end{tabular}

(B) S.Aureus

\begin{tabular}{c|c|c|c|c|c|c|c}
\hline 1 & 5 & $22 \pm 1.0$ & $24 \pm 0.0$ & $23 \pm 1.0$ & $29 \pm 1.0$ & 104.5 & 120.9 \\
\hline 2 & 10 & $24 \pm 0.44$ & $25 \pm 0.44$ & $24 \pm 0.54$ & $32 \pm 1.0$ & 100 & 128.0 \\
\hline 3 & 30 & $26 \pm 0.54$ & $25 \pm 0.54$ & $27 \pm 0.44$ & $35 \pm 1.0$ & 103.9 & 140
\end{tabular}

3.5.12. Accelerated stability study.

During the accelerated stability study, no significant change was observed in optimized formulation after six months with respect to its drug content and viscosity. Accelerated stability studies revealed high stability with the shelf life of 2 years as per the ICH guidelines. The drug degradation rate for optimized ocular formulation was found very low $\left(2.303 \times 10^{-4} \mathrm{day}^{-1}\right)$. Since the overall degradation was $<5 \%$, the tentative shelf life of 2 years can be assigned to the optimized formulation. The results are described in Table 12.

Table 12. Accelerated stability study of optimized in situ gelling systems.

\begin{tabular}{|c|c|c|c|c|}
\hline \multirow[t]{2}{*}{ Sr. No } & \multirow[t]{2}{*}{ Testing parameters } & \multicolumn{3}{|c|}{$\begin{array}{l}\text { Storage period (Months) at } 40 \pm 2^{\circ} \mathrm{C} \text { temperature and } \\
\text { NMT } 25 \% \mathrm{RH}\end{array}$} \\
\hline & & 0 Month & 3 Months & 6 Months \\
\hline 1 & Appearance & Clear & Clear & Clear \\
\hline 2 & Clarity $(\%)$ & 97.0 & 96.8 & 96.5 \\
\hline 3 & Viscosity (cps) & 120 & 118 & 119 \\
\hline 4 & Assay of Timolol maleate (\%) & $98.71 \%$ & $97.56 \%$ & $96.73 \%$ \\
\hline \multirow[t]{8}{*}{5} & \multicolumn{4}{|l|}{ Related substances } \\
\hline & Timolol related compound B (\%) & 0.005 & 0.015 & 0.081 \\
\hline & Timolol related compound D (\%) & 0.065 & 0.215 & 0.505 \\
\hline & Timolol related compound E (\%) & Not Detected & Not Detected & Not Detected \\
\hline & Timolol related compound C (\%) & 0.085 & 0.099 & 0.107 \\
\hline & Timolol related compound F (\%) & 0.56 & 0.68 & 0.95 \\
\hline & Any highest unspecified impurity (\%) & 0.001 & 0.098 & 0.18 \\
\hline & Total degradation products $(\%)$ & 0.716 & 1.107 & 1.823 \\
\hline 6 & $\mathrm{pH}$ & 5.8 & 6.1 & 5.9 \\
\hline 7 & Osmolality (mOsm/kg) & 300 & 310 & 308 \\
\hline 8 & In-vitro gelling capacity & +++ & +++ & +++ \\
\hline 9 & In-vitro drug release & $97.90 \%$ & $97.34 \%$ & $96.23 \%$ \\
\hline
\end{tabular}




\subsubsection{In-vivo ocular irritation study.}

In-vivo ocular irritation study revealed that the optimized formulation is non-irritant to the rabbit eyes. The formulation was very well tolerated and safe for use. Excellent ocular tolerance was noted. Therefore, optimized formulation was apparently as being appropriate and harmless for in-vivo utilization.

\subsubsection{Intraocular Pressure Reduction studies.}

The in-vivo pharmacodynamic study was carried out in an experimental model using two groups of normotensive Rabbits. The normal baseline for IOP was observed $15.05 \mathrm{mmHg}$. No significant day to day variation $(p=0.423)$ was observed in the normal IOP measurement for each animal. There was no significant difference $(\mathrm{p}=0.348)$ detected in both groups. The IOP reduction in both treated groups was found similar, as showed in Figure 10. To eliminate fluctuations due to diurnal IOP variations, the IOP values were expressed as the difference from the corresponding baseline values.

As described in the drug release study earlier, the In-vitro drug release profile showed sustained drug release, which is reassured by the in-vivo study, which showed a sustained therapeutic effect (reduction in IOP). The results suggest the potential of optimized formulation for sustained drug delivery. An IOP reduction study indicates that optimized formulation was equally efficacious with less variability in the reduction of IOP among the subjects when compared to marketed formulation. It also demonstrates that once-daily dosing is enough for the optimized formulation of Timolol maleate for ophthalmic delivery. It is noteworthy to mention that during the in-vivo pharmacodynamic study in rabbits, the eyelids, conjunctiva, and cornea were visually observed. The result of this test showed no opacity, conjunctival chemosis, redness, discharge, or no iris alteration. It can be said from the above observations that the optimized formulation is non-irritating.

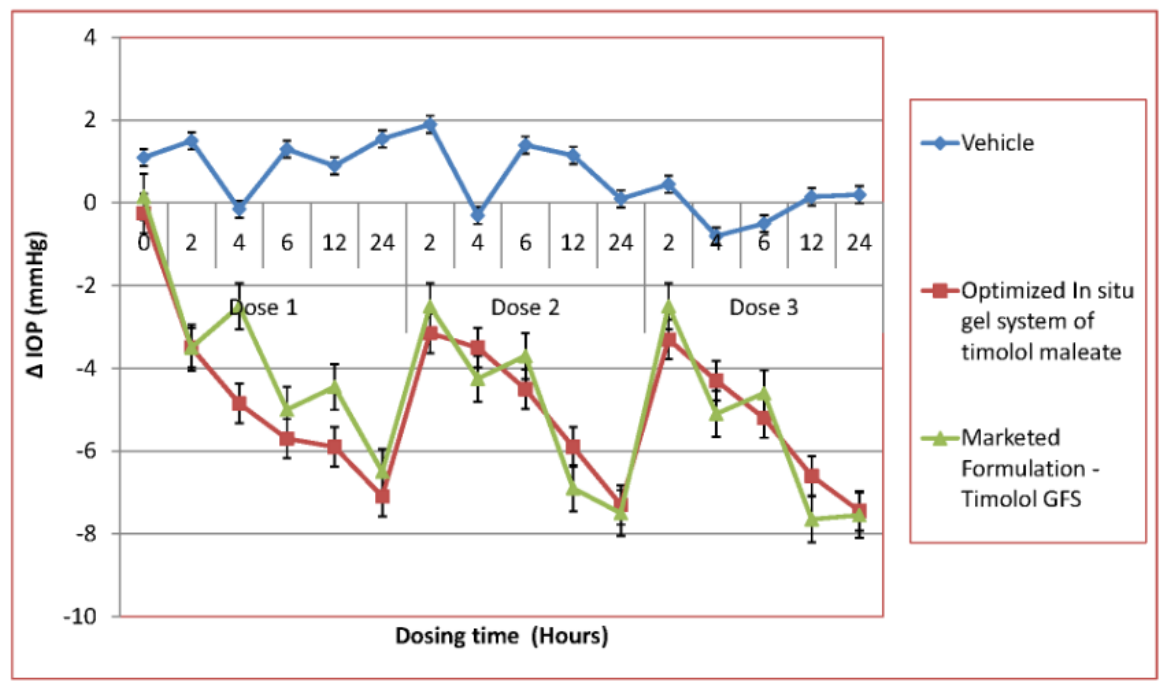

Figure 10. Graphical representation of data for the IOP study.

\section{Conclusions}

We have explored the development and optimization of in situ gelling systems of Timolol maleate for the ocular application using Box-Behnken design employing ion-sensitive gellan gum, mucoadhesive/pH-sensitive carbopol 934P and benzododecenium bromide as 
corneal permeability enhancer and preservative. Upon administration into the eye, the formulation transforms from solution to gel with desired viscosity state by simultaneous dilution with tear fluid, which increases ocular residence time. The optimized formulation exhibited all the desirable attributes of an ideal ophthalmic formulation and was found to be stable and non-irritant to the eye. The in-vitro drug release studies demonstrated that the prepared system exhibits controlled drug release as compared to the marketed ophthalmic solution. In-vivo study indicated that the present formulation would be able to offer benefits, such as increased drug residence time, controlled drug release, reduction in dose frequency, and thereby improve patient compliance. The developed formulation using simultaneous $\mathrm{pH}$ and ion mediated gelling provides high gelling capacity without increasing individual polymer concentration. The formulation provides a long precorneal residence time with a mucoadhesive polymer. The investigation also suggests the effectiveness of preservative as a penetration enhancer.

\section{Funding}

This research received no external funding.

\section{Acknowledgments}

The authors are grateful to Ms. Aneri Bhagat and Ms. Bindu Yadav, Research Scholars, Dept. of Pharmaceutical Technology, Ramanbhai Patel College of Pharmacy, Charotar University of Science and Technology (CHARUSAT) for their writing assistance.

\section{Conflicts of Interest}

The authors declare no conflict of interest.

\section{References}

1. Yadav, K.; Rajpurohit, R.; Sharma, S. Glaucoma: Current Treatment and Impact of Advanced Drug Delivery Systems. Life Sciences 2019, 221, 362-376,https://doi.org/10.1016/j.lfs.2019.02.029.

2. Chomchalao, P.; Nimtrakul, P.; Pham, D.; Tiyaboonchai, W. Development of Amphotericin B-Loaded Fibroin Nanoparticles: A Novel Approach for Topical Ocular Application. Journal of Materials Science 2020, 55, 5268-5279, https://doi.org/10.1007/s10853-020-04350-x.

3. Das, M.; Sharma, M.; Chandrul, M. A Review Of Potential Effect Of Nanotechnology And Control Drug Delivery System Introduce Into Ocular Drug Delivery System. International Journal of Trend in Scientific Research and Development 2019, 3, 28-34, https://doi.org/10.31142/ijtsrd23563.

4. Patel, G.C.; Parmar, V.K.; Patel, P.S. Stimuli-responsive polymers for ocular therapy. Stimuli Responsive Polymeric Nanocarriers for Drug Delivery Applications. Advanced drug delivery reviews 2019, 1, 463-489.

5. Wu, Y.; Liu, Y.; Li, X.; Kebebe, D.; Zhang, B.; Ren, J.; Lu, J.; Li, J.; Du, S.; Liu, Z. Research Progress Of In-Situ Gelling Ophthalmic Drug Delivery System. Asian Journal of Pharmaceutical Sciences 2019, 14,115,https://doi.org/10.1016/j.ajps.2018.04.008.

6. Lakhani, P.; Patil, A.; Majumdar, S. Recent Advances In Topical Nano Drug-Delivery Systems For The Anterior Ocular Segment. Therapeutic Delivery 2018, 9, 137-153, https://doi.org/10.4155/tde-2017-0088.

7. Majeed, A.; Khan, N. Ocular In Situ Gel: An Overview. Journal of Drug Delivery and Therapeutics2019, 9, 337-347, https://doi.org/10.22270/jddt.v9i1.2231.

8. Qian, Y.; Wang, F.; Li, R.; Zhang, Q.; Xu, Q. Preparation And Evaluation Of In Situ Gelling Ophthalmic Drug Delivery System For Methazolamide. Drug Development and Industrial Pharmacy 2010, 36, 13401347, https://doi.org/10.3109/03639041003801893.

9. Jumelle, C.; Gholizadeh, S.; Annabi, N.; Dana, R. Advances And Limitations Of Drug Delivery Systems Formulated As Eye Drops. Journal of Controlled Release 2020, 321, 1-22, https://doi.org/10.1016/j.jconrel.2020.01.057.

10. Kurniawansyah, I.S.; Rahmi, F.; Sopyan, I. pH triggered in-situ gelling ophthalmic drug delivery system. International Journal of Drug Delivery Technology 2018, 8, 1-5, https://doi.org/10.25258/ijddt.v8i01.11900. 
11. Chowhan, A.; Giri, T. Polysaccharide as Renewable Responsive Biopolymer for In Situ Gel In The Delivery Of Drug Through Ocular Route. International Journal of Biological Macromolecules 2020, 150,559572,https://doi.org/10.1016/j.ijbiomac.2020.02.097.

12. Gupta, H.; Velpandian, T.; Jain, S. Ion- And pH-Activated Novelin-Situgel System For Sustained Ocular Drug Delivery. Journal of Drug Targeting 2010, 18, 499-505, https://doi.org/10.3109/10611860903508788.

13. Luo, L.; Nguyen, D.; Lai, J. Dually Functional Hollow Ceria Nanoparticle Platform For Intraocular Drug Delivery: A Push Beyond The Limits Of Static And Dynamic Ocular Barriers Toward Glaucoma Therapy. Biomaterials 2020, 243, 119961-120027, https://doi.org/10.1016/j.biomaterials.2020.119961.

14. Sah, A.; Suresh, P. Medical Management Of Glaucoma: Focus On Ophthalmologic Drug Delivery Systems Of Timolol Maleate. Artificial Cells, Nanomedicine, and Biotechnology 2016, 45,448-459, https://doi.org/10.3109/21691401.2016.1160917.

15. Huang, J.; Peng, T.; Li, Y.; Zhan, Z.; Zeng, Y.; Huang, Y.; Pan, X.; Wu, C.; Wu, C. Ocular Cubosome Drug Delivery System For Timolol Maleate: Preparation, Characterization, Cytotoxicity, Ex Vivo, And In Vivo Evaluation. AAPS PharmSciTech 2017, 18 , 2919-2926, https://doi.org/10.1208/s12249-017-0763-8.

16. Makwana, S.B.; Patel,V.A.; Parmar, S.J. Development and characterization of in-situ gel for ophthalmic formulation containing ciprofloxacin hydrochloride. Results in pharma sciences 2016, 6, 1-6, https://doi.org/10.1016/j.rinphs.2015.06.001.

17. Souto, E.B.; Dias-Ferreira, J.; López-Machado, A.; Ettcheto, M.; Cano, A.; Camins Espuny, A.; Espina, M.; Garcia, M.L.;Sánchez-López, E. Advanced formulation approaches for ocular drug delivery: state-of-the-art and recent patents. Pharmaceutics 2019, 9, 1-29.

18. Destruel, P.; Zeng, N.; Seguin, J.; Douat, S.; Rosa, F.; Brignole-Baudouin, F.; Dufaÿ, S.; Dufaÿ-Wojcicki, A.; Maury, M.; Mignet, N.; Boudy, V. Novel In Situ Gelling Ophthalmic Drug Delivery System Based On Gellan Gum And Hydroxyethylcellulose: Innovative Rheological Characterization, In Vitro And In Vivo Evidence Of A Sustained Precorneal Retention Time. International Journal of Pharmaceutics 2020, 574, https://doi.org/10.1016/j.ijpharm.2019.118734.

19. Sun, J.; Zhou, Z. A Novel Ocular Delivery Of Brinzolamide Based On Gellan Gum: In Vitro And In Vivo Evaluation. Drug Design, Development and Therapy 2018, 12, 383-389, https://doi.org/10.2147/DDDT.S153405.

20. Hosny, K.; Rizg, W.; Khallaf, R. Preparation And Optimization Of In Situ Gel Loaded With RosuvastatinEllagic Acid Nanotransfersomes To Enhance The Anti-Proliferative Activity. Pharmaceutics 2020, 12, 263282, https://doi.org/10.3390/pharmaceutics12030263.

21. Wei, Y.; Li, C.; Zhu, Q.; Zhang, X.; Guan, J.; Mao, S. Comparison Of Thermosensitive In Situ Gels And Drug-Resin Complex For Ocular Drug Delivery: In Vitro Drug Release And In Vivo Tissue Distribution. International Journal of Pharmaceutics 2020, 578, 119184-119208, https://doi.org/10.1016/j.ijpharm.2020.119184.

22. De Souza Ferreira, S.; Moço, T.; Borghi-Pangoni, F.; Junqueira, M.; Bruschi, M. Rheological, Mucoadhesive And Textural Properties Of Thermoresponsive Polymer Blends For Biomedical Applications. Journal of the Mechanical Behavior of Biomedical Materials 2016, 55, 164178,https://doi.org/10.1016/j.jmbbm.2015.10.026.

23. Mishra, G.; Tamboli, V.; Mitra, A. Effect of Hydrophobic and Hydrophilic Additives On Sol-Gel Transition And Release Behavior Of Timolol Maleate From Polycaprolactone-Based Hydrogel. Colloid and Polymer Science 2011, 289, 1553-1562, https://doi.org/10.1007/s00396-011-2476-y.

24. Lavanya, K.; Chandran, S.; Balagangadharan, K.; Selvamurugan, N. Temperature- And Ph-Responsive Chitosan-Based Injectable Hydrogels for Bone Tissue Engineering. Materials Science and Engineering: $C$ 2020, 111, 110862-110882, https://doi.org/10.1016/j.msec.2020.110862.

25. Destruel, P.; Zeng, N.; Brignole-Baudouin, F.; Douat, S.; Seguin, J.; Olivier, E.; Dutot, M.; Rat, P.; Dufaÿ, S.; Dufaÿ-Wojcicki, A.; Maury, M.; Mignet, N.; Boudy, V. In Situ Gelling Ophthalmic Drug Delivery System For The Optimization Of Diagnostic And Preoperative Mydriasis: In Vitro Drug Release, Cytotoxicity And Mydriasis Pharmacodynamics. Pharmaceutics 2020, 12,360-379, https://doi.org/10.3390/pharmaceutics12040360.

26. Macedo-de-Araújo, R.; van der Worp, E.; González-Méijome, J. On-Eye Breakage And Recovery Of MiniScleral Contact Lens Without Compromise For The Ocular Surface. Contact Lens and Anterior Eye 2018, 41, 311-314, https://doi.org/10.1016/j.clae.2017.12.009.

27. Maulvi, F.; Choksi, H.; Desai, A.; Patel, A.; Ranch, K.; Vyas, B.; Shah, D. Ph Triggered Controlled Drug Delivery From Contact Lenses: Addressing The Challenges Of Drug Leaching During Sterilization And Storage. Colloids and Surfaces B: Biointerfaces $2017, \quad 157, \quad 72-82$, https://doi.org/10.1016/j.colsurfb.2017.05.064.

28. Keny, S.; Shah, K. Formulation And Development Of Extended Release Ocusert For Gemifloxacin Mesylate With Dexamethsaone. Research Journal of Pharmacy and Technology 2020, 13, 697702,https://doi.org/10.5958/0974-360X.2020.00133.X.

29. Boboridis, K.; Kozeis, N.; Konstas, A. Revisiting Ocular Allergy: Evaluating Symptoms, Benzalkonium Chloride and Efficacy Of Topical Ketotifen 0.025\%. Ocular Immunology and Inflammation 2019, 28, 188190, https://doi.org/10.1080/09273948.2018.1560478. 
30. Dong, Y.R.; Huang, S.W.; Cui, J.Z.; Yoshitomi, T. Effects of brinzolamide on rabbit ocular blood flow in vivo and ex vivo. International journal of ophthalmology 2018, 11, 719-725, https://doi.org/10.18240/ijo.2018.05.03.

31. Ranch, K.; Maulvi, F.; Naik, M.; Koli, A.; Parikh, R.; Shah, D. Optimization Of A Novel In Situ Gel For Sustained Ocular Drug Delivery Using Box-Behnken Design: In Vitro, Ex Vivo, In Vivo And Human Studies. International Journal of Pharmaceutics 2019, 554, 264-275, https://doi.org/10.1016/j.ijpharm.2018.11.016. 